\title{
Oxygen vacancies boosting ultra-stability of mesoporous ZnO-CoO@N-doped carbon microspheres for asymmetric supercapacitors
}

\author{
Di Yao ${ }^{1}$, Fulei Wang ${ }^{1}, \mathrm{Wu} \mathrm{Lei}^{1^{*}}$, Yan Hua ${ }^{1}$, Xifeng Xia ${ }^{1}$, Jinping $\mathrm{Liu}^{2}$ and Qingli Hao ${ }^{1^{*}}$
}

\begin{abstract}
Long-term cycling stability of pseudocapacitive materials is pursued for high-energy supercapacitors. Herein, the mesoporous zinc-cobalt oxide heterostructure@nitrogendoped carbon ( $\mathrm{ZnO}-\mathrm{CoO} @ \mathrm{NC}$ ) microspheres with abundant oxygen vacancies are self-assembled through a hydrothermal method combined with an annealing post-treatment. The multifunctional polyvinyl pyrrolidone (PVP) is used as a structure-directing agent, the precursor of $\mathrm{NC}$ and the initiator of abundant oxygen vacancies in zinc-cobalt oxide microspheres. XPS demonstrates the generation of surface oxygen vacancies resulted from the reduction effect of conductive NC, and further confirms the weaker interaction between the metal ions and oxygen atoms. As a result, the electrode based on $\mathrm{ZnO}-\mathrm{CoO} @ \mathrm{NC}$ in $2 \mathrm{~mol} \mathrm{~L}^{-1} \mathrm{KOH}$ shows enhanced capacitive performance with an excellent cycle stability of $92 \%$ retention of the initial capacitance after 40,000 charge-discharge cycles at $2 \mathrm{Ag}^{-1}$, keeping the morphology unchanged. The assembled asymmetric supercapacitor, graphene//ZnO-CoO@NC, also performs good cyclic stability with $94 \%$ capacitance retention after 10,000 cycles at $2 \mathrm{~A} \mathrm{~g}^{-1}$. The remarkable electrochemical performance of the self-assembled ZnO-CoO@NC composite is attributed to the mesoporous architecture, abundant oxygen vacancies, conductive $\mathrm{ZnO}$ scaffold for $\mathrm{CoO}$ crystals forming heterostructure of $\mathrm{ZnO}-\mathrm{CoO}$ and the high conductive NC layer covering outside of the multi-metal oxide nanoparticles. Hence, the $\mathrm{ZnO}$ CoO@NC holds great promise for high-performance energy storage applications.
\end{abstract}

Keywords: supercapacitor, zinc oxide, cobaltous oxide, doped carbon, cycling stability, heterostructure

\section{INTRODUCTION}

Supercapacitors (SCs) are attractive alternatives to batteries with a great application potential and attracting ever-growing attention recently, due to their intriguing features such as high power capabilities, long cycle life and rapid charge/discharge processes [1-5]. But the low energy density of SCs, especially the electric double layer capacitors (EDLCs) based on carbonous materials, must be boosted further for the demand of next generation electronic devices. Pseudocapacitors as another kind of SCs, based on pseudocapacitive materials storing charges through Faradaic reactions, may reach several times higher specific capacitance and energy density than normal EDLCs. With unique characteristics like environmental benignity and high specific capacitance, transition metal oxides are intensively explored as redox oxides with high pseudocapacitance for SCs. Cobalt oxides, like $\mathrm{Co}_{3} \mathrm{O}_{4}[6,7]$ and $\mathrm{CoO}$, also have high theoretical specific capacitance [8]. However, they suffer from the inferior rate capability and cycling stability because of their poor electrical conductivity and volume change during the charge/discharge process [9]. Therefore, combining electrically conductive components is considered to accelerate the electron transfer rate of cobalt-based composites. For instance, $\mathrm{CoO} @ \mathrm{NiO}$ nano-architectures on the activated carbon textile [10], CoO@CNT- $x$ nanocomposite [11], $\mathrm{Co}_{3} \mathrm{O}_{4} @ \mathrm{PDA}-\mathrm{rGO}$ [12], and gold nanoparticles-decorated $\mathrm{rGO}-\mathrm{ZnCo}_{2} \mathrm{O}_{4}$ nanocomposite [13] were successfully prepared for SCs and exhibited enhanced electrochemical performances. With the advantages of mechanical flexibility, excellent conductivity and easiness of combining with other materials, $\mathrm{ZnO}$

\footnotetext{
${ }^{1}$ Key Laboratory for Soft Chemistry and Functional Materials, Ministry of Education, School of Chemical Engineering, Nanjing University of Science and Technology, Nanjing 210094, China

${ }^{2}$ Chemical Engineering and Life Science and State Key Laboratory of Advanced Technology for Materials Synthesis and Processing, Wuhan University of Technology, Wuhan 430070, China

* Corresponding authors (emails: leiwuhao@njust.edu.cn (Lei W); qinglihao@njust.edu.cn (Hao Q))
} 
often acts as good electrical and mechanical supports for other components as electrode materials in SCs $[14,15]$, which can enhance the electrochemical performances of metal oxide as supercapacitor electrode materials with better electric conductivity such as $\mathrm{ZnO} / \mathrm{CoO}$ nanosheets microspheres [16] and hierarchical corn skeleton-like $\mathrm{ZnO@CoO} \mathrm{[17].} \mathrm{However,} \mathrm{most} \mathrm{of} \mathrm{them} \mathrm{are} \mathrm{still} \mathrm{defective}$ for the relatively poor cycling stability.

Very recently, the introduction of oxygen vacancies into metal oxides to improve the electrochemical performance for SCs has also received great attention [1822]. Oxygen vacancies in $\mathrm{MnO}_{2}$ [19] and hematite [20] could significantly improve the conductivity of metal oxides and accelerate the kinetics of surface redox reaction. Kim et al. [23] reported oxygen vacancies enhanced pseudocapacitive charge storage properties of $\mathrm{MoO}_{3-x}$ because the larger interlayer spacing promoted faster charge storage kinetics.

In this study, we fabricated an ultra-stable pseudocapacitive electrode material, ZnO-CoO@nitrogen-doped carbon (NC), for SCs with high electrochemical performance enhanced by oxygen vacancies (Fig. 1). The multifunctional polyvinyl pyrrolidone (PVP) was used as a structure-directing agent, the precursor of $\mathrm{NC}$ and the initiator of abundant oxygen vacancies in zinc-cobalt oxide microspheres. Meanwhile, PVP and conductive $\mathrm{ZnO}$ nanocrystals combined with $\mathrm{CoO}$ nanocrystals to fabricate cubic-like or prism heterostructure $\mathrm{ZnO}-\mathrm{CoO}$ nanobricks as the self-assembled backbone, later converted to the self-assembled mesoporous ZnO-CoO@NC oval microspheres. The presence of electric conductive $\mathrm{ZnO}$ and $\mathrm{NC}$ efficiently suppressed the collapse of the microspherical structure during the charge and discharge processes, thereby remarkably improving the cycling stability. The electrochemical performance of the $\mathrm{ZnO}$ -
CoO@NC electrode in $2 \mathrm{~mol} \mathrm{~L}^{-1} \mathrm{KOH}$ manifested its extremely remarkable cycling stability with $92 \%$ specific capacitance retention after 40,000 cycles at $2 \mathrm{~A} \mathrm{~g}^{-1}$, high specific capacitance and good rate capability. Furthermore, a solid-state asymmetric supercapacitor (ASC), assembled with $\mathrm{ZnO}-\mathrm{CoO} @ \mathrm{NC}$ as the positive electrode and graphene as the negative electrode, exhibited considerable electrochemical performance with excellent cycling stability. These electrochemical results demonstrate that the as-prepared mesoporous heterostructured $\mathrm{ZnO}$ $\mathrm{CoO} @ \mathrm{NC}$ assembly is a prominent candidate for supercapacitor electrodes.

\section{EXPERIMENTAL SECTION}

\section{Synthesis of ZnO-CoO@NC}

All the chemicals are analytical grade and used without further purification. The fabrication of $\mathrm{ZnO}-\mathrm{CoO} @ \mathrm{NC}$ was designed by a simple hydrothermal route in the presence of PVP (K-30) followed by an annealing process in $\mathrm{N}_{2}$. In detail, PVP $(500 \mathrm{mg}), \mathrm{Zn}\left(\mathrm{NO}_{3}\right)_{2} \cdot 6 \mathrm{H}_{2} \mathrm{O}(1 \mathrm{mmol})$ and $\mathrm{Co}\left(\mathrm{NO}_{3}\right)_{2} \cdot 6 \mathrm{H}_{2} \mathrm{O}(2 \mathrm{mmol})$ were dispersed in absolute ethanol $(30 \mathrm{~mL})$ and stirred for $20 \mathrm{~min}$ to form pink transparent solution. Subsequently, $5 \mathrm{~mL}$ of $1.2 \mathrm{~mol} \mathrm{~L}^{-1}$ $\left(\mathrm{NH}_{4}\right)_{2} \mathrm{CO}_{3}$ aqueous solution was slowly dropped into the above mixed solution and stirred for another $20 \mathrm{~min}$. After that, the above mixed solution was transferred into a Teflon-lined stainless steel autoclave $(50 \mathrm{~mL})$. The autoclave was sealed and held at $150^{\circ} \mathrm{C}$ under autogenous pressure for $8 \mathrm{~h}$ in an electric oven and then cooled down to room temperature naturally. The resulted pink $\mathrm{Zn}-\mathrm{Co}-$ $C$ precursor was collected by centrifugation and rinsed several times with deionized water and ethanol, and subsequently dried in air at $60^{\circ} \mathrm{C}$ for $10 \mathrm{~h}$. The final product was obtained after being annealed in $\mathrm{N}_{2}$ at $400^{\circ} \mathrm{C}$

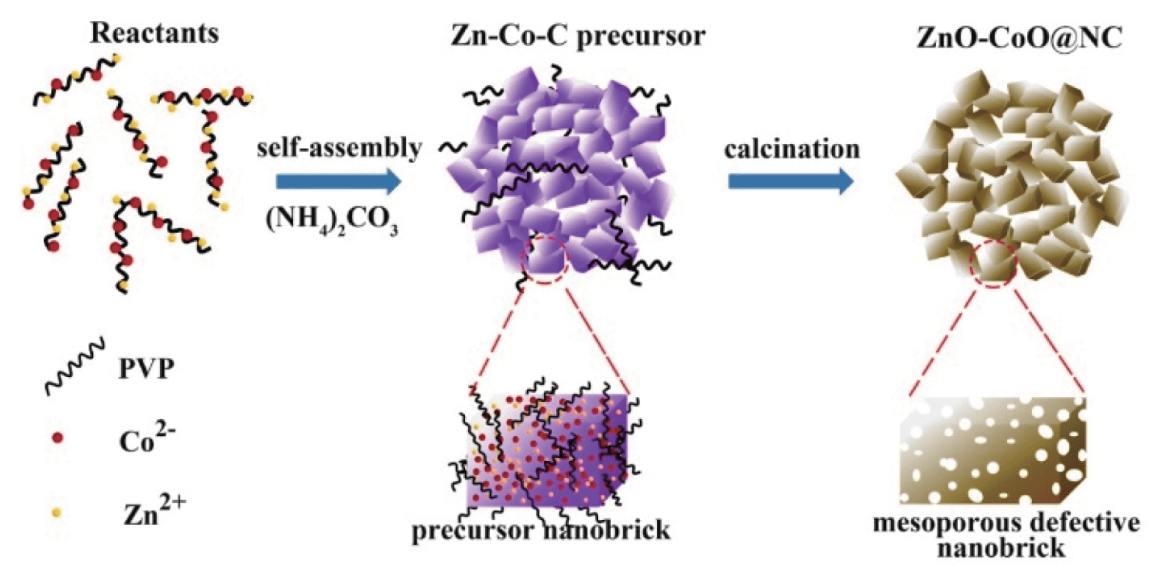

Figure 1 Schematic of the formation process of $\mathrm{ZnO}-\mathrm{CoO} @ \mathrm{NC}$ microspheres. 
for $2 \mathrm{~h}$ at a ramp rate of $2^{\circ} \mathrm{C} \mathrm{min}^{-1}$, and named $\mathrm{ZnO}$ CoO@NC. For comparison, the individual $\mathrm{ZnO}, \mathrm{CoO}$ and the composite of $\mathrm{ZnO}-\mathrm{CoO}$ were also prepared under the similar procedure at the same condition without PVP, just with relative single metal nitrate or the mixed metal nitrates, respectively.

\section{Structural characterization}

Powder X-ray diffraction (XRD) was carried out on Bruker Advanced D8 Diffractometer (Germany) with monochromatized $\mathrm{Cu} \mathrm{Ka}(\lambda=1.5418 \AA)$ radiation at $40 \mathrm{kV}$ and $40 \mathrm{~mA}$. X-ray photoelectron spectroscopy (XPS) data were recorded on Perkin-Elmer PHI 5300 with an $\mathrm{Al} \mathrm{Ka}(h v=1486.7 \mathrm{eV}) \mathrm{X}$-ray as the exciting source. Transition electron microscopy (TEM) investigation was performed by JEOL JEM-2100 instrument (Japan) under an acceleration voltage of $200 \mathrm{kV}$. Field emission scanning electron microscopy (FE-SEM) images and energy dispersive X-ray spectroscopy (EDS, Oxford) elemental mapping were provided by FEI Quanta 250FEG scanning electron microscope at an acceleration voltage of $3.0 \mathrm{kV}$. The nitrogen adsorption-desorption isotherm measurements were performed on a Micromeritics ASAP 2020 volumetric adsorption analyzer at $77 \mathrm{~K}$. BrunauerEmmett-Teller (BET) method was utilized to calculate the specific surface area. Thermogravimetric analysis (TGA) was steered on DGT-60 (Shimadzu, Japan). The combination of five instrument, thermogravimetry/differential scanning calorimetry (TG/DSC+3 1600LF, Mettler-Toledo)-Fourier transform infrared spectroscopy (FTIR, Nicolet iS50)-gas chromatograohy(GC)-mass spectrometry (MS) (Agilent 7890B-5977B) was used to investigate the thermal stability and chemical components.

\section{Electrochemical measurements}

All of the electrochemical measurements, including cyclic voltammetry (CV) tests and galvanostatic charge/discharge (GCD) as well as electrochemical impedance spectroscopy (EIS) were carried out in $2 \mathrm{~mol} \mathrm{~L}^{-1} \mathrm{KOH}$ aqueous solution at a CHI760C workstation (Shanghai Chenhua instrument $\mathrm{Co}$, Ltd). A three-electrode configuration was adopted in the experiment, in which $\mathrm{Hg} / \mathrm{HgO}$ and platinum foil were used as reference and counter electrodes, respectively. A viscous slurry was obtained by mechanically mixing the active material $(80 \mathrm{wt} \%)$, acetylene black (10 wt\%) and polytetrafluoroethylene (PTFE) binder $(10 \mathrm{wt} \%)$, and then the slurry was pressed onto nickel foam and dried at $60^{\circ} \mathrm{C}$ for $12 \mathrm{~h}$ subsequently, which was used as the working electrode. The typical mass loading of the electrode was about $4 \mathrm{mg}$. The con- dition of EIS tests was as follows: alternating current voltage amplitude $5 \mathrm{mV}$, and the frequency range from $1 \times 10^{-3} \mathrm{~Hz}$ to $1 \times 10^{5} \mathrm{~Hz}$ at open circuit potential.

The ASC was assembled with two pieces of nickel foam electrodes face-to-face separated by the solid-state polymer gel electrolyte. The ZnO-CoO@NC and graphene (friendly supported by Ningbo Morsh TECH. CO., LTD) were used as active materials for positive and negative electrodes, respectively. The polymer gel electrolyte was prepared by mixing $3.4 \mathrm{~g}$ of $\mathrm{KOH}$ and $6 \mathrm{~g}$ of polyvinyl alcohol (PVA) in $60 \mathrm{~mL}$ deionized water at $80^{\circ} \mathrm{C}$ with stirring until the solution became clear. Both the positive and negative electrodes were dipped into the gel solution for a few minutes to soak the gel electrolyte. After being solidified at room temperature, two pieces of electrodes separated by the $\mathrm{PVA} / \mathrm{KOH}$ gel film were used to assemble an ASC wrapped with PARAFILM. The solidstate polymer PVA/KOH gel film served as both the separator and electrolyte.

The specific capacitance calculated from the CV curves is according to the following equation:

$Q_{c}=\int i(u) \mathrm{d} u /(m v \times 3.6)\left(\mathrm{mA} \mathrm{h} \mathrm{g}^{-1}\right)$,

where $Q_{c}$ is the specific capacitance, $i(u)(\mathrm{A})$ is the current, $u(\mathrm{~V})$ is the potential, and $m(\mathrm{~g})$ and $v\left(\mathrm{mV} \mathrm{s}^{-1}\right)$ are the mass of active materials and scan rates, respectively.

The specific capacitance calculated from the discharge curves in GCD at various current densities is according to the following equation:

$Q_{\mathrm{g}}=(I \times \Delta t) /(m \times 3.6)\left(\mathrm{mA} \mathrm{h} \mathrm{g}^{-1}\right)$,

where $Q_{\mathrm{g}}$ is the specific capacitance, and $I(\mathrm{~A})$ is the constant current for charge/discharge. $\Delta t(\mathrm{~s})$ and $m(\mathrm{~g})$ designate total discharge time and mass of active materials during discharge, respectively.

Energy density $(E)$ of the supercapacitor device is derived from the following equation:

$E=0.5 \mathrm{Q} \times \Delta V\left(\mathrm{~W} \mathrm{~h} \mathrm{~kg}^{-1}\right)$,

where $Q$ and $\Delta V$ are the specific capacitance and potential drop during discharge of the supercapacitor, respectively.

Power density $(P)$ is calculated from the following equation:

$P=E / \Delta t\left(\mathrm{~W} \mathrm{~kg}^{-1}\right)$,

where $E$ is the energy density, $\Delta t$ is the discharge time.

The coulombic efficiency is calculated from the following equation:

$\eta=t_{\mathrm{d}} / t_{\mathrm{c}} \times 100 \%$,

where $t_{\mathrm{d}}$ and $t_{\mathrm{c}}$ are the discharge and charge time, respectively. 


\section{RESULTS AND DISCUSSION}

\section{Structure and morphology}

Fig. 2a demonstrates the XRD pattern of the pink Zn-Co$\mathrm{C}$ precursor. Compared with the standard patterns of $\mathrm{ZnCO}_{3}$ and $\mathrm{CoCO}_{3}$, the diffraction peaks of $\mathrm{Zn}-\mathrm{Co}-\mathrm{C}$ precursor at $25.1^{\circ}, 32.5^{\circ}$ and $53.8^{\circ}$ belong to (012), (104) and (018) of the cubic $\mathrm{ZnCO}_{3}$ (JCPDS No. 08-0449), and the diffraction peaks at $25.1^{\circ}, 32.6^{\circ}$ and $54^{\circ}$ are assigned to (012), (104) and (018) of the cubic $\mathrm{CoCO}_{3}$ (JCPDS No. 11-0692). Therefore, the $\mathrm{Zn}-\mathrm{Co}-\mathrm{C}$ precursor contains cubic $\mathrm{ZnCO}_{3}$ and $\mathrm{CoCO}_{3}$ crystals.

Fig. $2 \mathrm{~b}$ shows the XRD pattern of the final product ZnO-CoO@NC microspheres after the annealing process, together with those of standard patterns of $\mathrm{ZnO}$ and CoO. Obviously, the peaks at $32.0^{\circ}, 34.6^{\circ}, 36.6^{\circ}, 47.9^{\circ}$, $56.1^{\circ}, 63.0^{\circ}$ and $69.0^{\circ}$ are close to $31.8^{\circ}, 34.4^{\circ}, 36.3^{\circ}, 47.5^{\circ}$, $56.6^{\circ}, 62.9^{\circ}$ and $69.1^{\circ}$ of the standard pattern of the hexagonal zincite-structure of $\mathrm{ZnO}$ phase (JCPDS No. 361451), which can be assigned to the diffraction planes of (100), (002), (101), (102), (110), (103) and (201) of n-type $\mathrm{ZnO}$. While, the diffraction peaks of $\mathrm{ZnO}-\mathrm{CoO} @ N C$ at $36.6^{\circ}, 42.6^{\circ}, 61.7^{\circ}, 77.5^{\circ}$ may be assigned to the (111), (200), (220) and (222) of the cubic CoO (JCPDS No. 481719), which shows the relative standard diffraction peaks

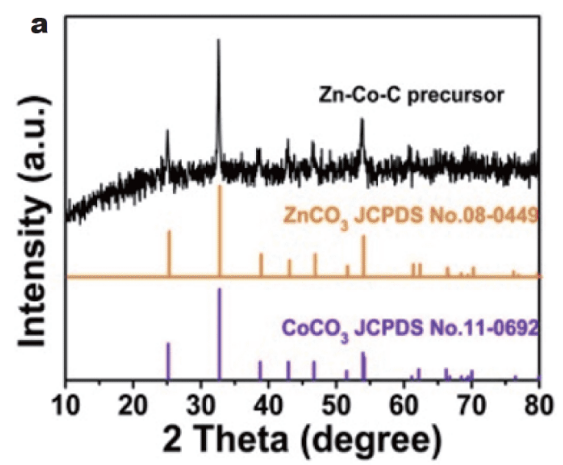

at $36.5^{\circ}, 42.4^{\circ}, 61.5^{\circ}, 77.5^{\circ}$. In addition, there are no more peaks observed for other crystalline components, and no obvious diffraction peaks attributed to NC because of its amorphous state and its small proportion compared with the metal oxides. Therefore, it is suggested that the microspheres of ZnO-CoO@NC may be assembled with a large amount of nanocrystals mainly containing $\mathrm{ZnO}$ and $\mathrm{CoO}$ phases. However, the XRD peaks of $\mathrm{ZnO}$ and $\mathrm{CoO}$ phases in the $\mathrm{ZnO}-\mathrm{CoO} @ \mathrm{NC}$ microspheres have some slight shifts. The shift may be related to the interface coupling of n-type $\mathrm{ZnO}$ and p-type $\mathrm{CoO}$ to form herterostructure of $\mathrm{ZnO}-\mathrm{CoO}$ and the surface oxygen vacancy defects generated during the annealing process, which will be proved further by XPS measurement.

To further confirm the chemical structure of the composite microspheres, FTIR spectra were collected for the precursors of $\mathrm{ZnO}-\mathrm{CoO}$ and $\mathrm{ZnO}-\mathrm{CoO} @ \mathrm{NC}$ and pure PVP, as shown in Fig. 2c. For both $\mathrm{Zn}-\mathrm{Co}-\mathrm{C}$ and $\mathrm{Zn}$-Co precursors, there are three same strong peaks at 1391, 859 and $744 \mathrm{~cm}^{-1}$, corresponding to the asymmetrical stretching vibration $(v)$, in-plane bending vibration $(\beta)$ and out-of-plane bending vibration $(\gamma)$ of $\left[\mathrm{CO}_{3}\right]^{2-}$ [24], indicating that the two precursors contain the same metal carbonates, i.e. $\mathrm{ZnCO}_{3}$ and $\mathrm{CoCO}_{3}$, which are well in agreement with the results of XRD. Interestingly, there
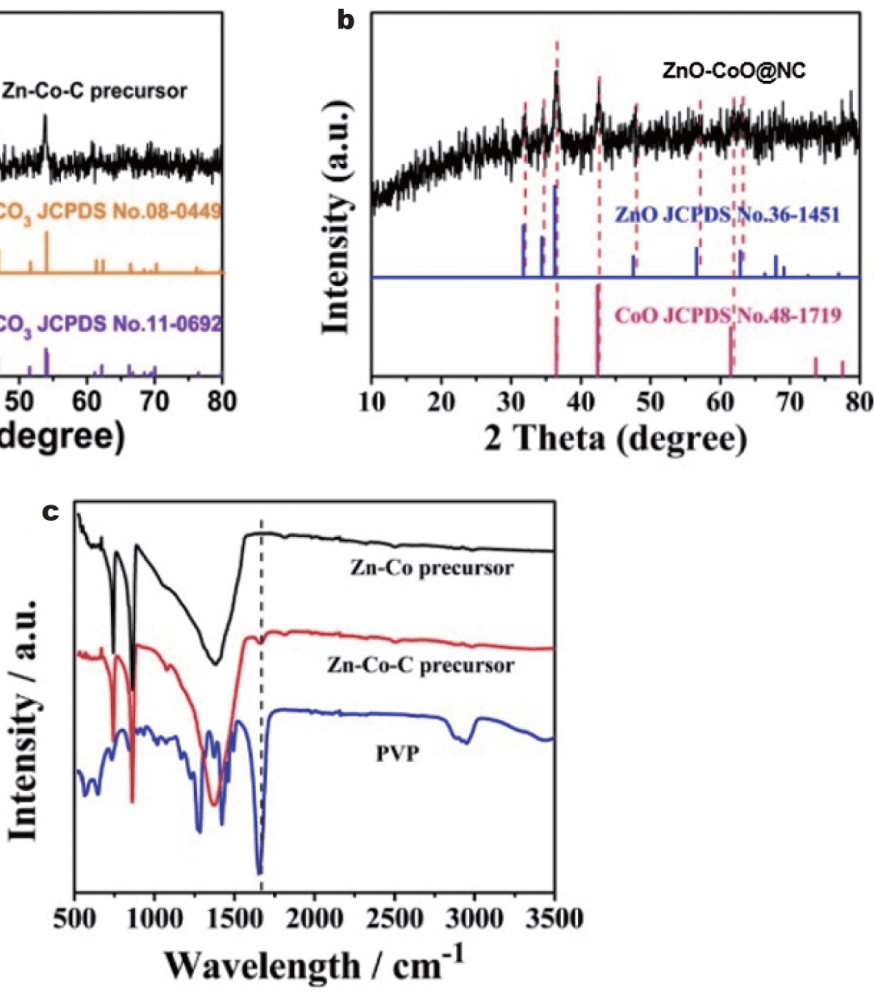

Figure 2 XRD patterns of Zn-Co-C precursor (a) and ZnO-CoO@NC (b); FTIR spectra of the Zn-Co precursor, Zn-Co-C precursor and PVP (c). 
is an additional vibrational peak at $\sim 1660 \mathrm{~cm}^{-1}$ in the FTIR spectrum of $\mathrm{Zn}$-Co-C precursor, compared with the $\mathrm{Zn}$-Co precursor. This weak peak is very close to the strongest absorption peak at $\sim 1652 \mathrm{~cm}^{-1}$ of pure PVP, which is assigned to the carbonyl bond $(\mathrm{C}=\mathrm{O})$ vibration of PVP [25]. According to the preparation of the $\mathrm{Zn}-\mathrm{Co}-$ $\mathrm{C}$ precursor, the appearance of the peak at about $1660 \mathrm{~cm}^{-1}$ should be assigned to the $\mathrm{C}=\mathrm{O}$ stretching vibration of PVP combined with $\mathrm{ZnCO}_{3}-\mathrm{CoCO}_{3}$ microspheres. The peak shift of carbonyl bond is due to the strong interaction of PVP and the metal ions in the composite of $\mathrm{ZnCO}_{3}-\mathrm{CoCO}_{3}$.

The survey XPS spectrum (Fig. 3a) clearly shows the surface chemical composition of $\mathrm{ZnO}-\mathrm{CoO} @ \mathrm{NC}$ con- taining $\mathrm{Zn}, \mathrm{Co}, \mathrm{O}$ and $\mathrm{C}$ elements. Fig. 3b-e display the typical high resolution XPS spectra of C 1s, Zn 2p, Co $2 p$, $\mathrm{O} 1 \mathrm{~s}$ of $\mathrm{ZnO}-\mathrm{CoO} @ \mathrm{NC}$ and $\mathrm{O} 1 \mathrm{~s}$ of $\mathrm{ZnO}-\mathrm{CoO}$. The $\mathrm{C} 1 \mathrm{~s}$ region of ZnO-CoO@NC in Fig. 3b can be deconvoluted into four peaks centered at 284.8, 286.3, 287.8 and $289.2 \mathrm{eV}$, belonging to $\mathrm{C}-\mathrm{C}, \mathrm{C}-\mathrm{O}, \mathrm{C}=\mathrm{O}$ and $\mathrm{N}-\mathrm{C}=\mathrm{O}$, respectively [26,27]. The peak at $289.2 \mathrm{eV}$ proves the existence of NC, although nitrogen is not shown in the full-range XPS spectrum in Fig. 3a due to its low content (0.37 at\%, Table S1 in Supplementary information). The deconvoluted $\mathrm{N}$ 1s band (Fig. S1a) can be split into two peaks at 398.0 and $400.3 \mathrm{eV}$ corresponding to pyrrolic $\mathrm{N}$ and pyridinic $\mathrm{N}$, respectively $[28,29]$. As shown in Table S1, the atomic contents of C and $\mathrm{N}$ are $17.07 \%$ and
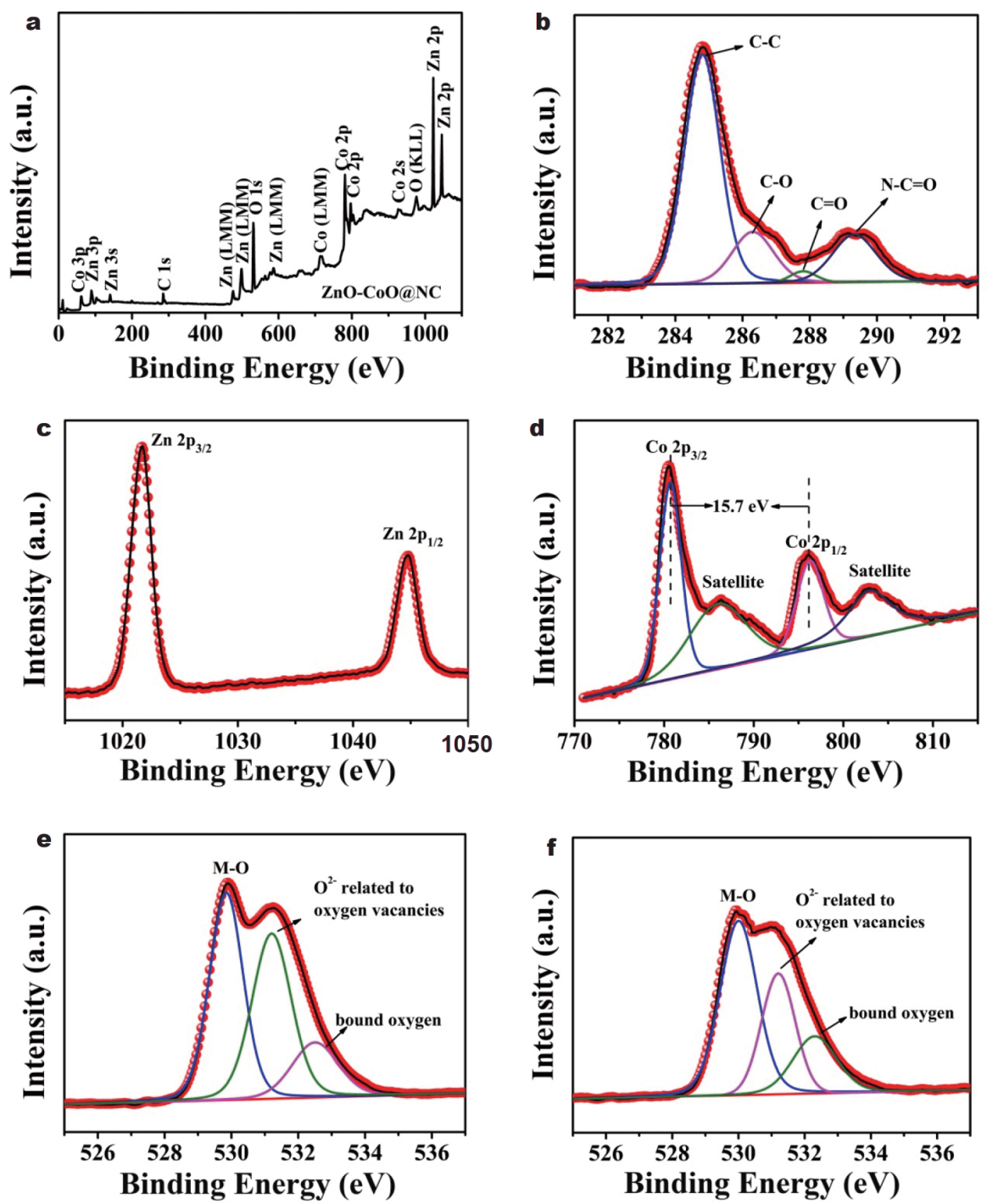

Figure 3 XPS spectra of ZnO-CoO@NC: survey spectrum (a), C 1s (b), Zn 2p (c), Co 2p (d), O 1s of ZnO-CoO@NC (e), O 1s of ZnO-CoO (f). 
$0.37 \%$ respectively. The atomic ratio of Co to $\mathrm{Zn}$ is calculated to be 1.5:1, which is smaller than $2: 1$ of the feeding ratio and that of EDX, taking the error of XPS measurement for surface elements into account.

The high resolution $\mathrm{Zn} 2 \mathrm{p}$ spectrum (Fig. 3c) of $\mathrm{ZnO}-$ CoO@NC presents two peaks centered at 1021.4 and $1044.3 \mathrm{eV}$, which can be attributed to $\mathrm{Zn} 2 \mathrm{p}_{3 / 2}$ and $\mathrm{Zn}$ $2 \mathrm{p}_{1 / 2}$ respectively, indicating the presence of $\mathrm{ZnO}$ without metal $\mathrm{Zn}$ [30]. Moreover, these two values are slightly smaller than those of ZnO-CoO (1021.9 and $1045.2 \mathrm{eV}$ shown in Fig. S1b). The binding energies of Co $2 p_{3 / 2}$ and Co $2 \mathrm{p}_{1 / 2}$ of $\mathrm{ZnO}-\mathrm{CoO} @ \mathrm{NC}$ (Fig. 3d) are separately observed at 780.4 and $796.1 \mathrm{eV}$, and the two prominent shake-up satellite peaks (785.8 and $802.4 \mathrm{eV}$ ) are also observed in the Co $2 \mathrm{p}$ peak. A difference of $15.9 \mathrm{eV}$ between the binding energies of Co $2 \mathrm{p}_{3 / 2}$ and Co $2 \mathrm{p}_{1 / 2}$ is unique for $\mathrm{Co}^{2+}$ in $\mathrm{CoO}$ [31]. No metal $\mathrm{Co}^{0}$ is observed. Moreover, according to the reference [32], the two peaks at 780.4 and $796.1 \mathrm{eV}$ obviously shift to the low binding energy compared with those commercial $\mathrm{CoO}$ and those of $\mathrm{ZnO}-\mathrm{CoO}$ (780.6 and $796.5 \mathrm{eV}$ shown in Fig. S1c). This shift means that $\mathrm{Co}^{2+}$ has a tendency to the weaker interaction with oxygen atom due to the reduction of $\mathrm{NC}$ under calcination condition. Therefore, it indicates the existence of oxygen vacancies on the surface of $\mathrm{ZnO}$ $\mathrm{CoO} @ \mathrm{NC}$, due to the absence of $\mathrm{Co}^{0}$ in the sample.

To gain more insight into the oxygen deficiency in the ZnO-CoO@NC, the O1s XPS was deconvoluted for both ZnO-CoO@NC (Fig. 3e) and ZnO-CoO (Fig. 3f). The $\mathrm{O} 1 \mathrm{~s}$ spectra of the two samples can be described similarly by three obvious bands at 529.9, 531.2 and $532.6 \mathrm{eV}$, respectively. The $\mathrm{O} 1 \mathrm{~s}$ peak at $529.9 \mathrm{eV}$ is associated with the $\mathrm{O}^{2-}$ in metal oxide phase, and the highest binding energy component located at $532.6 \mathrm{eV}$ usually corresponds to the loosely bound oxygen on the surface of the samples. The middle one at $531.2 \mathrm{eV}$ is attributed to the $\mathrm{O}^{2-}$ in the oxygen vacancy regions of $\mathrm{ZnO}$ in the matrix of ZnO-CoO@NC and $\mathrm{ZnO}-\mathrm{CoO}$ microspheres [33]. Moreover, for $\mathrm{ZnO}-\mathrm{CoO} @ \mathrm{NC}$, the area ratio of the peak at $531.2 \mathrm{eV}$ to that at $529.9 \mathrm{eV}$ is about 0.93 , great higher than that of $\mathrm{ZnO}-\mathrm{CoO}$ (0.54, Fig. 3f) obtained in absence of PVP. This further confirms that a large amount of oxygen vacancies exist on the surface of the $\mathrm{ZnO}$ CoO@NC microspheres. It suggests that the small amount of NC derived from PVP may reduce the surface $\mathrm{ZnO}$ to effectively produce the large amount of oxygen vacancies in ZnO-CoO@NC microspheres, due to the absence of metal. The oxygen vacancies of $\mathrm{CoO}$ were also confirmed by the analysis of Co 2p XPS (Fig. 3d). But it is difficult to distinguish the oxygen vacancy peak of $\mathrm{CoO}$ which usually presents at $\sim 533 \mathrm{eV}$ [32] and is merged into the band of $532.6 \mathrm{eV}$ in $\mathrm{ZnO}-\mathrm{CoO} @ \mathrm{NC}$ and $\mathrm{ZnO}-\mathrm{CoO}$ samples. Therefore, all these results from XPS analyses indicate the large amount of oxygen vacancies exist in the $\mathrm{ZnO}-\mathrm{CoO} @ \mathrm{NC}$ microspheres resulting from the reduction of carbon by calcination in $\mathrm{N}_{2}$. It further reflects the importance of PVP in the current work, which plays an important role in acting as the precursor of $\mathrm{NC}$ and producing abundant oxygen vacancies in $\mathrm{ZnO}-\mathrm{CoO} @ \mathrm{NC}$ during its carbonation process.

Thus, according to the above results, the chemical structure of the final product $\mathrm{ZnO}-\mathrm{CoO} @ \mathrm{NC}$ is composed of $\mathrm{ZnO}, \mathrm{CoO}$ and a small amount of $\mathrm{NC}$, which results from the carbonation of the PVP molecules anchored on the metal carbonates under nitrogen atmosphere during the annealing process. Moreover, the carbon can act as a reducing agent for the slight reduction of metal oxides, which leads to the formation of large oxygen vacancies on the surface of $\mathrm{ZnO}-\mathrm{CoO} @ \mathrm{NC}$. These oxygen vacancies are expected to improve the electrochemical performance of the $\mathrm{ZnO}-\mathrm{CoO} @ \mathrm{NC}$ used as an electrode material for supercapacitors [18,19,23,32].

The TGA curve of $\mathrm{ZnO}-\mathrm{CoO} @ \mathrm{NC}$ was collected under air atmosphere from $50-600^{\circ} \mathrm{C}$ (Fig. S2), which drops down at the lower temperature, and then starts to climb up at $\sim 200^{\circ} \mathrm{C}$ with about $3 \%$ weight increase until $600^{\circ} \mathrm{C}$. This is because the cobalt with low valence state is oxidized by oxygen at high temperature, meanwhile oxygen vacancies can also be oxidized, leading to the weight increase of the sample. Although the loss of carbon will cause the decrease of the sample weight, the sum of total weight loss among the increase of oxygen and loss of carbon produces a positive value, which means the total weight of the sample increases with the temperature increase in air atmosphere. Therefore, unfortunately, the TGA analysis cannot provide percentage of carbonaceous content.

The morphology and architecture of the $\mathrm{ZnO}$ CoO@NC were characterized by FE-SEM and TEM as shown in Fig. 4. The typical SEM image shown in Fig. 4a reveals that the $\mathrm{ZnO}-\mathrm{CoO} @ \mathrm{NC}$ is entirely composed of uniform oval microspheres and obtained in large-scale yield. Further observation (Fig. $4 \mathrm{~b}$ ) suggests that the individual microsphere is elliptical and consists of analogous prism nanobricks. The long axis of the oval $\mathrm{ZnO}$ CoO@NC microsphere is about $3.6 \mu \mathrm{m}$ and the short axis is about $3 \mu \mathrm{m}$ as seen in Fig. 4b. The $\mathrm{ZnO}-\mathrm{CoO} @ \mathrm{NC}$ microsphere is comprised of various nanobricks with the edge length ranging from 100 to $200 \mathrm{~nm}$ (Fig. 4b inset). The EDS element mapping analysis in Fig. $4 \mathrm{c}$ reveals the 

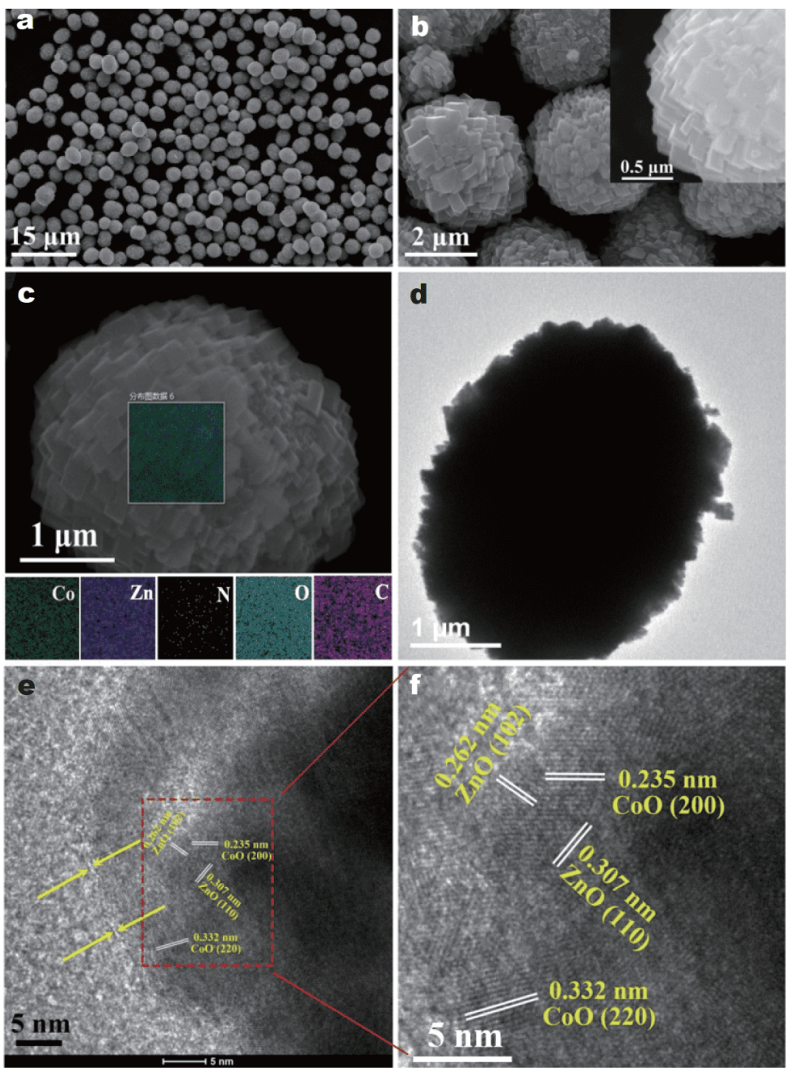

Figure 4 SEM (a-c) and TEM (d, e) images of ZnO-CoO@NC. Element mapping images for $\mathrm{Co}, \mathrm{Zn}, \mathrm{N}, \mathrm{O}$ and $\mathrm{C}$ are shown in (c). (f) The magnification of the selected area in (e).

ZnO-CoO@NC composite contains Co, Zn, O, C and N elements. What's more, the element content of the $\mathrm{ZnO}$ CoO@NC according to EDS is listed in Table S2. The ratio of Co to $\mathrm{Zn}$ is $2: 1$, exactly consistent with the feeding ratio of the reactants. Since the measurement of EDS represents the element information of the bulk materials, the ratio is close to the real elemental ratio of the final sample. While the 1.5:1 value from XPS only presents the surface information of the microspheres. The TEM image (Fig. 4d) further confirms the oval microsphere which is in good agreement with the SEM observation. From the high-resolution TEM image in Fig. $4 \mathrm{e}$ and its magnification in Fig. 4f, some part of the lattice fringes can be observed, but some of them become blurred in the prism nanobrick, indicating the distortion of the metal oxide lattice structure resulting from the oxygen vacancies [32]. The relative interplanar space values of 0.262 and $0.307 \mathrm{~nm}$ are assigned to the (102) and (110) of $\mathrm{ZnO}$, and 0.235 and $0.332 \mathrm{~nm}$ correspond to the (200) and (220) of $\mathrm{CoO}$, respectively. The results agree with that from XRD. Moreover, a carbon layer about 1-2 $\mathrm{nm}$ is observed out of the edge of the nanobrick, as marked between arrows in Fig. 4e. The thin carbon layer derived from the carbonation of PVP may improve the conductivity of the $\mathrm{ZnO}$ $\mathrm{CoO}$ composite due to its intrinsic feature of good electrical conductivity, proved by EIS measurement later.

Unfortunately, the ZnO-CoO@NC microsphere is too large to be clearly detected in detail by TEM. Actually, there are many mesopores in the nanobricks which are mainly generated by the decomposition of $\mathrm{ZnCO}_{3}$ and $\mathrm{CoCO}_{3}$, and the self-assembly process. This can be deduced from the light edges of nanobricks in TEM images (Fig. 4d). These mesopores could not be observed clearly in the body of nanobrick because of the large size of microspheres. It can be proved by BET characterization. As shown in Fig. 5, the nitrogen adsorption isotherm (Fig. 5a) is a typical type-IV curve according to the IUPAC classification, indicating the existence of a mesoporous structure [34]. The BET surface area is $47.6 \mathrm{~m}^{2} \mathrm{~g}^{-1}$, and the pore size distribution (Fig. 5b) shows peaks centered at around 2.4 and 5-15 nm for the larger pores. The mesopores result from the decomposition of metal carbonates and PVP, and the larger pores might be from the self-assembly of prism nanobricks. This result coincides with those of SEM and TEM characterization. The porosity of ZnO-CoO@NC microspheres can facilitate the transfer of ions and electrons at the electrode/ electrolyte interface and alleviate the volume change during the charge-discharge process, thus improving the electrochemical performance [18,23,32,35].

Known from the morphology and BET analyses, such a hierarchical microstructure of $\mathrm{ZnO}-\mathrm{CoO} @ \mathrm{NC}$ with large surface area and mesopores is expected to be accessible for the electrolytes, and provide more active sites and more transportation routes for ions. These merits may subsequently contribute to the enhancement of electrochemical performance of the ZnO-CoO@NC microspheres used as electrode materials for supercapacitors. Moreover, the large number of mesopores may increase the buffering effect during the process of ion transport, and the N-doped carbon "skin" can hinder the dissolution in the electrolyte, which are helpful to improve the cycling stability of the ZnO-CoO@NC microspheres [36].

The influence of PVP content on the morphology of the composite was also systematically investigated. The TEM images of various $\mathrm{ZnO}-\mathrm{CoO} @ \mathrm{NC}$ obtained with different contents $(0,0.25,0.5,0.75$ to $1.0 \mathrm{~g})$ of PVP are shown in Fig. S3a-e. The $\mathrm{ZnO}-\mathrm{CoO}$ composite obtained without PVP shows un-regular micro-agglomerates with an average size of about $6.0 \times 5.6 \mu \mathrm{m}$, in which the large prism nanobrick edge length is more than $1.6 \mu \mathrm{m}$ (Fig. S3a). 

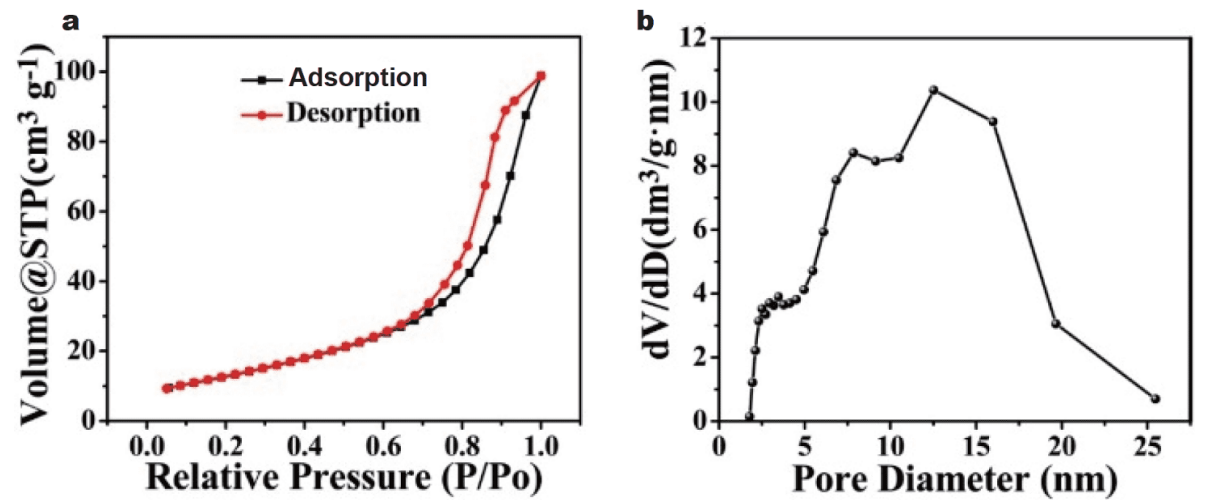

Figure 5 (a) $\mathrm{N}_{2}$ adsorption-desorption isotherm of $\mathrm{ZnO}-\mathrm{CoO} @ \mathrm{NC}$. (b) The corresponding pore size distribution curve calculated by Barrett-JoynerHalenda method.

However, all composites of ZnO-CoO@NC obtained with PVP (Fig. S3b-e) keep self-assembled oval microspheres with different average sizes of microspheres and nanobricks. As the PVP content increases $(0,0.25,0.5,0.75$, $1.0 \mathrm{~g}$ ), the monodisperse microsphere becomes smaller from $0,0.25$ to $0.5 \mathrm{~g}$, and almost keeps unchanged with the increasing of PVP from 0.5 to $1.0 \mathrm{~g}$. It is noted that the size of nanobricks in microspheres also decreases from $\sim 1600$ to $\sim 300, \sim 200 \mathrm{~nm}$, and then, gradually increases to $\sim 220 \mathrm{~nm}$ and $\sim 330 \mathrm{~nm}$, for $0,0.25,0.5,0.75$ and $1.0 \mathrm{~g}$, respectively in Fig. S3a-e. The phenomena can be explained that the growth of nanobricks without PVP keeps normal growth rates and those covered with PVP are greatly reduced, but excessive amount of PVP may inhibit their regulatory effects due to their own interactions [37]. Therefore, in our work, PVP is a good structure-controlling agent and growth modifier to control the growth of metal carbonate nanobricks in $\mathrm{Zn}-\mathrm{Co}-\mathrm{C}$, as widely used by researchers $[37,38]$, as well as a precursor of NC, and reducing agent for producing abundant oxygen vacancies in $\mathrm{ZnO}-\mathrm{CoO} @ \mathrm{NC}$.

With the similar size of oval microspheres, the mesoporous $\mathrm{ZnO}-\mathrm{CoO} @ \mathrm{NC}$ obtained from $0.5 \mathrm{~g}$ PVP contains the smallest nanobricks. Therefore, the optimized $\mathrm{ZnO}$ CoO@NC shows the large surface area and mesopores $\left(47.6 \mathrm{~m}^{2} \mathrm{~g}^{-1}\right.$, Fig. 5). As we all know, the consumed charge in a supercapacitor is directly proportional to specific surface area of the active materials, which provides us with the ability to tune the electrochemical properties of the ZnO-CoO@NC composite as electrode materials for supercapacitors.

\section{Electrochemical properties}

In order to gain the optimized electrochemical perfor- mance of ZnO-CoO@NC as electrode materials for supercapacitors, the effect of PVP content $(0,0.25,0.5,0.75$, $1.0 \mathrm{~g}$ ) on the CV, GCD, rate capabilities and EIS results were investigated (Fig. 6a, d).

As a consequence, the CV curves of the five samples with similar redox peak shape show apparently different integrated areas at a scan rate of $20 \mathrm{mV} \mathrm{s}^{-1}$ in a potential range of $0-0.65 \mathrm{~V}$ in $2 \mathrm{~mol} \mathrm{~L}^{-1} \mathrm{KOH}$ (Fig. 6a). As the content of PVP increases from 0 to $0.25,0.5,0.75$ and $1.0 \mathrm{~g}$, the response current in CV curves firstly increases and reaches the maximum when PVP content is $0.5 \mathrm{~g}$, indicating the largest specific capacitance due to the large surface area and large amount of mesopores (BET data in Fig. 5). Further increasing PVP content ( 0.75 and $1.0 \mathrm{~g}$ ) leads to the response current decreasing, which is consistent with the evolution of morphology change in Fig. S3. All samples demonstrate two main pairs of redox peak couples with wide $\mathrm{CV}$ areas, meaning the combination of double layered capacitive and pseudocapacitive behaviors.

In order to assign these peaks and determine the function of various components, the $\mathrm{CV}$ curves of single $\mathrm{ZnO}, \mathrm{CoO}, \mathrm{ZnO}-\mathrm{CoO}$ and blank $\mathrm{Ni}$ foam electrodes at lower scanning rate of $5 \mathrm{mV} \mathrm{s}^{-1}$ are demonstrated in Fig. S4a, b for comparison. Compared with $\mathrm{CoO}, \mathrm{ZnO}$ and ZnO-CoO@NC, Ni foam shows very small CV curve, illustrating negligible capacitance contribution (Fig. S4b). In the CVs, ZnO-CoO@NC possesses the redox pair at lower potentials $(\sim 0.3$ and $\sim 0.2 \mathrm{~V})$ than $\mathrm{CoO}$ and $\mathrm{ZnO}$, due to the conversion reaction between $\mathrm{Co}^{2+} / \mathrm{Co}^{3+}$, and the other pair at higher potentials $(\sim 0.5$ and $\sim 0.4 \mathrm{~V})$ is mainly corresponding to $\mathrm{Co}^{3+} / \mathrm{Co}^{4+}[9]$ and the Faradaic process of the surface reversible reaction of $\mathrm{ZnO}(\mathrm{ZnO}+$ $\mathrm{K}^{+}+\mathrm{e}^{-} \rightarrow \mathrm{ZnOK}$ ) [39]. However, the capacitance con- 


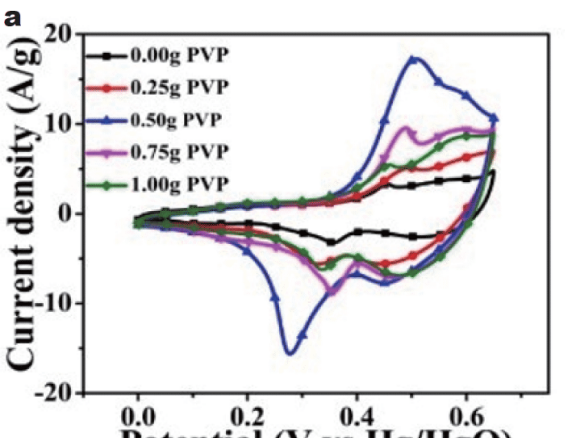

Potential (V vs Hg/HgO)
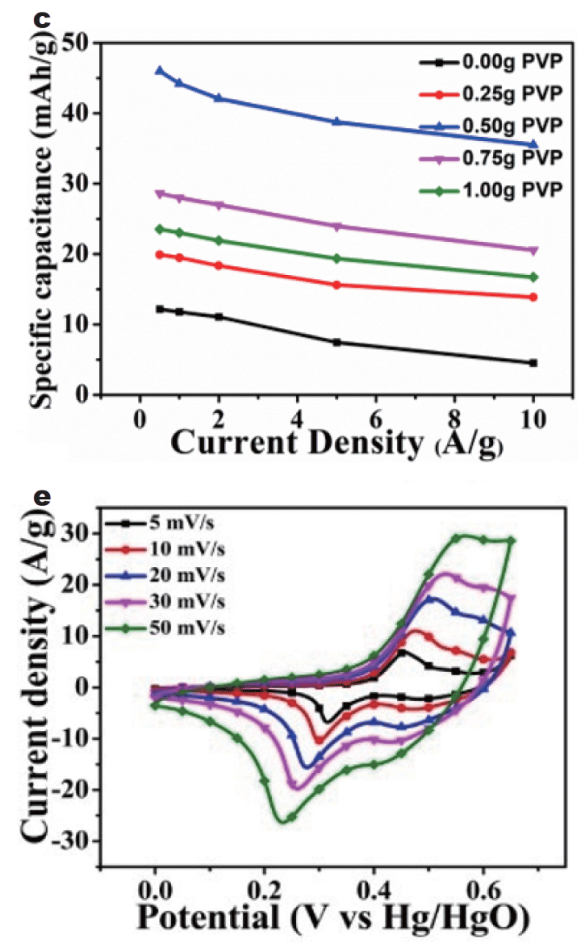

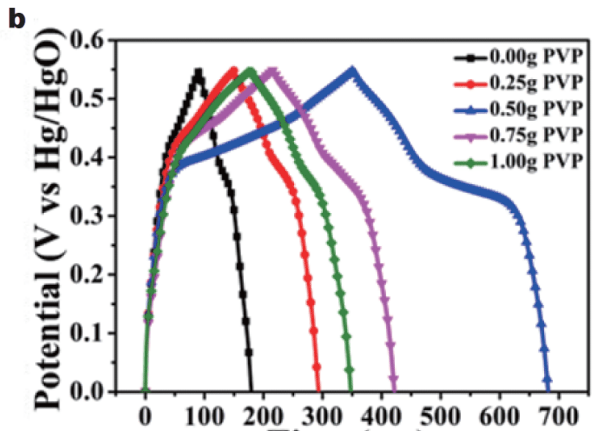

Time (sec)
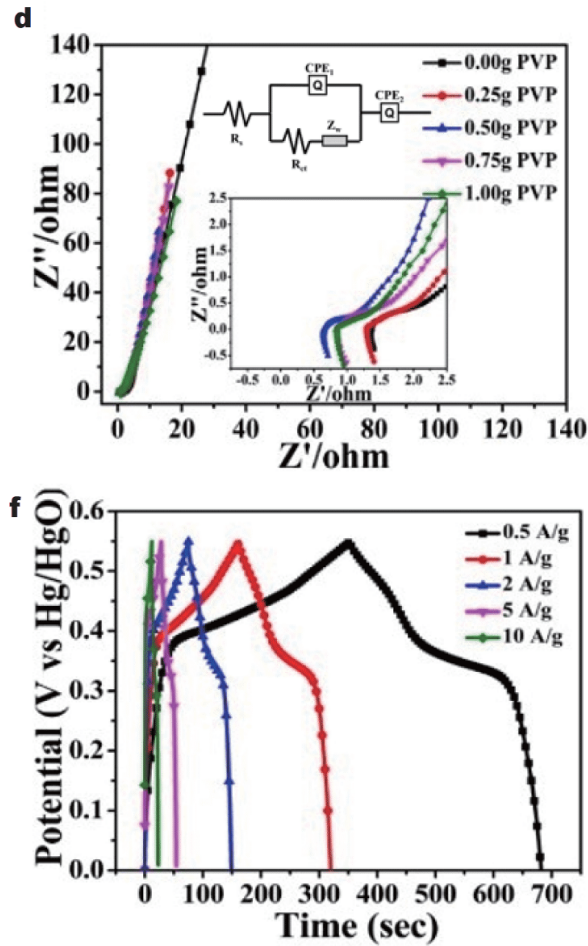

Figure 6 Electrochemical measurements of the samples obtained from different PVP contents $(0-1.0 \mathrm{~g})$ in $2 \mathrm{~mol} \mathrm{~L}^{-1} \mathrm{KOH}$. (a) CV curves at $20 \mathrm{mV} \mathrm{s}^{-1}$; (b) GCD curves at $0.5 \mathrm{~A} \mathrm{~g}^{-1}$; (c) specific capacitance at various current densities from 0.5 to $10 \mathrm{~A} \mathrm{~g}^{-1}$; (d) EIS curves (the inset shows the equivalent circuit and a magnified EIS spectrum); (e) CV curves at different scan rates (5-50 mV s${ }^{-1}$ ) and (f) GCD curves at different current densities $\left(0.5-10 \mathrm{~A} \mathrm{~g}^{-1}\right)$ of $\mathrm{ZnO}-\mathrm{CoO} @ \mathrm{NC}(0.5 \mathrm{~g} \mathrm{PVP})$ in $2 \mathrm{~mol} \mathrm{~L}^{-1} \mathrm{KOH}$.

tribution of single $\mathrm{ZnO}$ is much less than that of single $\mathrm{CoO}$. According to Equation (1), the capacitance values of single $\mathrm{ZnO}, \mathrm{CoO}, \mathrm{ZnO}-\mathrm{CoO}$ and $\mathrm{ZnO}-\mathrm{CoO} @ \mathrm{NC}$ from $0.5 \mathrm{~g}$ PVP are calculated to be 1.87, 16.1, 14.6 and $50.4 \mathrm{~mA} \mathrm{~h} \mathrm{~g}^{-1}\left(11.2,96.3,87.7\right.$ and $\left.302.6 \mathrm{~F} \mathrm{~g}^{-1}\right)$, respectively. For the $\mathrm{ZnO}-\mathrm{CoO}$ composite with a mass ratio of $1: 2$, the specific capacitance $\left(14.6 \mathrm{~mA} \mathrm{~h} \mathrm{~g}^{-1}, 87.7 \mathrm{~F} \mathrm{~g}^{-1}\right)$ is higher than the calculated value of $11.3 \mathrm{~mA} \mathrm{~h} \mathrm{~g}^{-1}$ $\left(67.8 \mathrm{~F} \mathrm{~g}^{-1}\right)$ because of the physically mixed composite of $\mathrm{ZnO}$ and $\mathrm{CoO}$ with the same ratio. It means the introduction of $\mathrm{ZnO}$ nanocrystals into $\mathrm{CoO}$ plays an important role in enhancing the total specific capacitance of the $\mathrm{ZnO}-\mathrm{CoO}$ composite due to the significant synergetic effect. Moreover, the big difference in capacitance of $\mathrm{ZnO}-\mathrm{CoO} @ \mathrm{NC}$ from $\mathrm{ZnO}, \mathrm{CoO}$ and $\mathrm{ZnO}-\mathrm{CoO}$ no doubt results from the contribution of the $\mathrm{NC}$ layer, abundant oxygen vacancies, and the synergetic effect among components in the mesoporous structure. Especially compared with $\mathrm{ZnO}-\mathrm{CoO}$ in current density and capacitance, $\mathrm{ZnO}-\mathrm{CoO} @ \mathrm{NC}$ exhibits much larger redox peaks with about 7-fold current density higher than that of $\mathrm{ZnO}$ $\mathrm{CoO}$, and larger integrated area. The results further indicate the contribution of oxygen vacancies and NC layers in conductivity and capacitance. 
Fig. $6 \mathrm{~b}$ further displays the comparison of GCD curves for the five samples at $0.5 \mathrm{~A} \mathrm{~g}^{-1}$. A distinct plateau region appears during the charge/discharge process, which is consistent with the CV curves. The charging and discharging curves are all symmetric, evidencing fully reversible electrochemistry of $\mathrm{ZnO}$ and $\mathrm{CoO}$. As expected, the optimized sample demonstrates the longest discharging time than the other four samples. Obviously, the performance of GCD is consistent with that of CVs for the five samples. The specific capacitance $\left(C_{\mathrm{sp}}\right)$ based on the discharge curves of GCD was calculated according to Equation (2) and plotted in Fig. 6c. The specific capacitance is $12.2,19.9,46.0,28.6,23.5 \mathrm{~mA} \mathrm{~h} \mathrm{~g}^{-1}(79.6,130.3$, $301.0,187.2,154.0 \mathrm{~F} \mathrm{~g}^{-1}$ ) at $0.5 \mathrm{~A} \mathrm{~g}^{-1}$, for the electrode materials obtained with $0,0.25,0.5,0.75$, and $1.0 \mathrm{~g}$ PVP, and decreases to $4.5,13.9,35.5,20.5,16.7 \mathrm{~mA} \mathrm{~h} \mathrm{~g}^{-1}$ (29.5, 90.7, 232.4, 134.5, 109.4 $\mathrm{F} \mathrm{g}^{-1}$ ) at $10 \mathrm{~A} \mathrm{~g}^{-1}$, respectively for the five samples. The decrease in specific capacitance of each sample is attributed to the diffusion effect limiting the ionic motion in the electrolyte at high scan rate, resulting in low electrochemical utilization of the active materials [14]. Furthermore, the specific capacitance values of all ZnO-CoO@NC electrodes slightly decrease at a much slower rate than that of $\mathrm{ZnO}-\mathrm{CoO}$ (Fig. 6c), demonstrating the good rate performance of $\mathrm{ZnO}$ $\mathrm{CoO} @ \mathrm{NC}$ due to the NC layer. Interestingly, the $\mathrm{ZnO}$ CoO@NC obtained from $0.5 \mathrm{~g}$ PVP exhibits the best rate capability. About $78 \%$ of the specific capacitance of $\mathrm{ZnO}$ CoO@NC from $0.5 \mathrm{~g}$ PVP is retained when the current density increases from 0.5 to $10 \mathrm{~A} \mathrm{~g}^{-1}$. The outstanding rate capability and superior electrochemical performance of the ZnO-CoO@NC electrode can be attributed to the optimized crystal size, the large surface area, and the NC layer on the surface of $\mathrm{ZnO}-\mathrm{CoO}$.

All the EIS spectra of the five samples show good capacitive behaviors with the vertical lines close to $90^{\circ}$ at the low frequency area (Fig. 6d), due to their mesoporous structures. Moreover, all of them show the negligible semicircles in the high frequency region. Fitted with ZSimpWin software, the distinctions in the chargetransfer resistance $\left(R_{\mathrm{ct}}\right)$ among the five curves can be easily observed (Table S3). The curve for the $\mathrm{ZnO}-\mathrm{CoO}$ without NC (0 $\mathrm{g}$ PVP) shows the largest $R_{\mathrm{ct}}$ $\left(3.62 \Omega \mathrm{cm}^{-2}\right)$, while those of four $\mathrm{ZnO}-\mathrm{CoO} @ \mathrm{NC}$ samples exhibit relatively lower values in the range of $1.77-2.64 \Omega \mathrm{cm}^{-2}$, in which the $\mathrm{ZnO}-\mathrm{CoO} @ \mathrm{NC}$ obtained from $0.5 \mathrm{~g}$ PVP displays the smallest $R_{\mathrm{ct}}$ value of $1.77 \Omega \mathrm{cm}^{-2}$. The EIS result indicates the presence of NC and oxygen vacancies can remarkably improve the electrical conductivity of the composites contributing to the rate performance. Moreover, the ZnO-CoO@NC obtained from $0.5 \mathrm{~g}$ PVP exhibits the highest electrical conductivity. As proved by many groups [29-33], the presence of oxygen vacancies can greatly improve the electron/charge transfer rate (or conductivity) and other electrochemical properties. However, it is difficult for us to distinguish the contribution of carbon and oxygen vacancies for simultaneous generation of them.

On the basis of the comprehensive analyses of $\mathrm{CV}$, rate capability and EIS, the sample with $0.5 \mathrm{~g}$ PVP serves as the optimized electrode material in further study for supercapacitors. The excellent rate performance of the optimized electrode materials can be demonstrated by the $\mathrm{CV}$ curves at various scanning rates $\left(5-50 \mathrm{mV} \mathrm{s}^{-1}\right)$ and GCD curves at different current densities $\left(0.5\right.$ to $\left.10 \mathrm{~A} \mathrm{~g}^{-1}\right)$ in Fig. 6e, f. All CV curves with two pairs of redox peaks maintain good shapes with the increasing scan rates (Fig. 6e). In addition, the oxidation/reduction peaks gradually shift towards higher/lower potential, respectively, indicating the internal resistance and polarization effect during the Faradaic processes due to the redox reaction controlled by the charge transfer dynamics $[40,41]$. However, the slight shift suggests the good reversibility and the fast charge/discharge response of the electrode and the excellent rate capability $[42,43]$. Moreover, the linear relationship of redox current response to the root of scan rate (Fig. S5) indicates $\mathrm{ZnO}$ CoO@NC exhibits the semi-infinite diffusion controlled redox reactions, which benefits from the mesoporous microstructure and the improved conductivity due to the incoming carbon layer and rich oxygen vacancies. The wide CV slopes imply the large capacitance consisting of double-layered capacitance from mesoporous structure and pseudocapacitance from the $\mathrm{ZnO}-\mathrm{CoO}$ matrix. The non-linear charge/discharge profiles of GCD (Fig. 6f) further verify the combination of pseudocapacitive and double-layered behaviors of the electrode at various current densities $\left(0.5-10 \mathrm{~A} \mathrm{~g}^{-1}\right)$ in the potential window from 0 to $0.55 \mathrm{~V}$. The well maintained GCD shapes at various current densities confirm the excellent rate performance of ZnO-CoO@NC (0.5 g PVP).

In order to further assess the practical value of the optimized materials, the cycling stability of the $\mathrm{ZnO}$ CoO@NC (0.5 g PVP) electrode was tested by repeating charge/discharge measurements at $2 \mathrm{Ag}^{-1}$ (Fig. 7a). Clearly, the specific capacitance gradually increases firstly and then decreases slightly in the following cycles. The activation process results in the increase of capacitance in the initial cycles, which is confirmed by the previous work [41]. At the 5000th cycle, the specific capacitance of the 

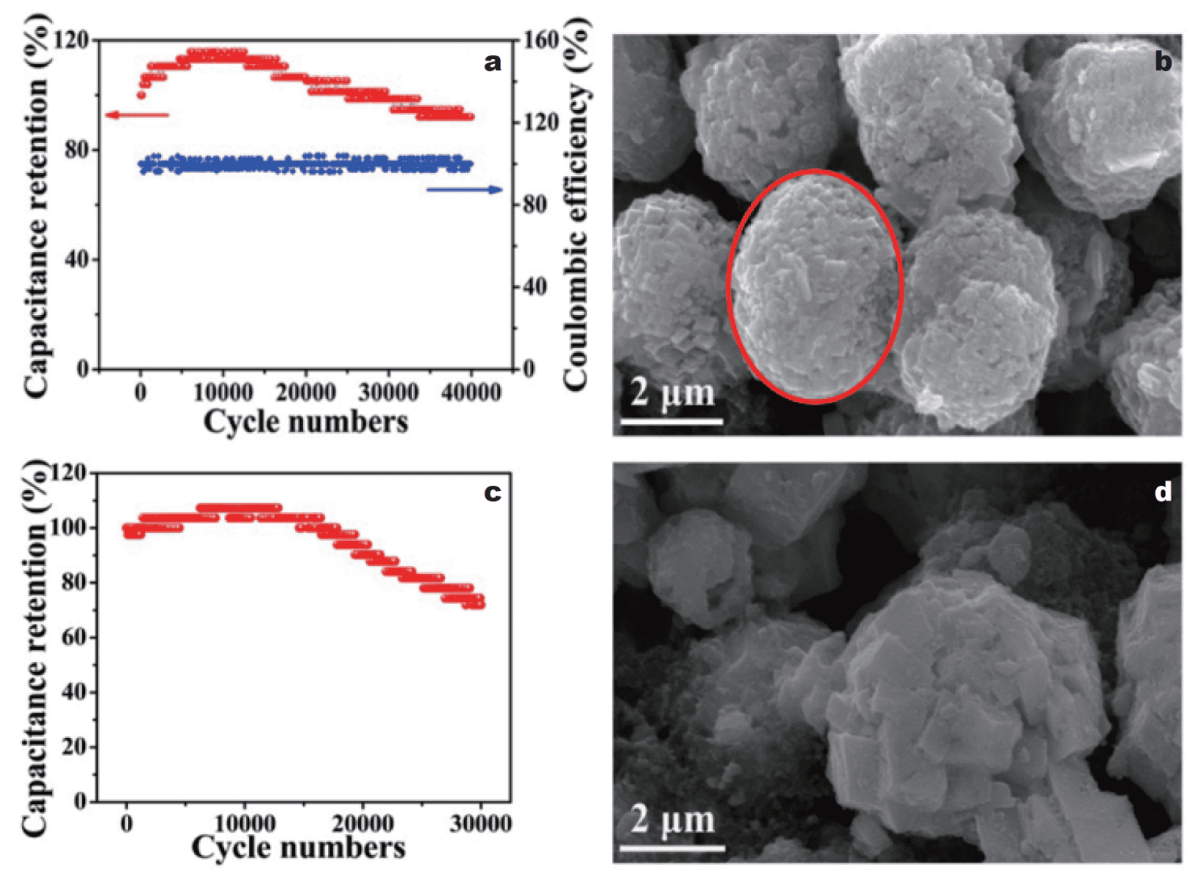

Figure 7 (a) Cycling stability and coulombic efficiency of ZnO-CoO@NC electrode, (b) SEM image of ZnO-CoO@NC after duration test over 40,000 cycles, (c) cycling stability of $\mathrm{ZnO}-\mathrm{CoO}$ electrode, and (d) SEM image of $\mathrm{ZnO}-\mathrm{CoO}$ after duration test over 30,000 cycles.

ZnO-CoO@NC electrode reaches its highest value (113\% of its initial specific capacitance). And after 30,000 cycles, the capacitance still maintains $100 \%$ of the initial value. Even after 40,000 continuous charge-discharge cycles, about $92 \%$ of the initial capacitance can still be retained. The results reveal the excellent cyclic stability of the $\mathrm{ZnO}$ CoO@NC electrode in $\mathrm{KOH}$ aqueous electrolyte. The corresponding coulombic efficiency deduced from Equation (5) is more than $97 \%$ during the long-term charge-discharge cycling for 40,000 , which confirms the electrochemical stability and the feasible redox reactions of the ZnO-CoO@NC electrode obtained from $0.5 \mathrm{~g}$ PVP. The morphology of this electrode after 40,000 charge/ discharge cycles at $2 \mathrm{~A} \mathrm{~g}^{-1}$ was also characterized by SEM (Fig. 7b). It is worthy to mention that there are nearly no significant structural changes of the $\mathrm{ZnO}-\mathrm{CoO} @ \mathrm{NC}$ oval microspheres after 40,000 cycles of charging/discharging, which further confirms the excellent cycling stability of ZnO-CoO@NC (0.5 g PVP). The additional irregular substance on some microspheres is acetylene black added in the process of electrode preparation. Moreover, the element component of $\mathrm{ZnO}-\mathrm{CoO} @ \mathrm{NC}$ after 40,000 charge/discharge cycles was also confirmed by EDS element mapping analysis (Fig. S6). All the signals of the five element of Co, Zn, O, C and $\mathrm{N}$ elements can still be found in the element mapping images.
For comparison, the $\mathrm{ZnO}-\mathrm{CoO}$ as electrode material was also tested under the same conditions for long-term cycling (Fig. 7c) with the SEM image of this electrode after duration test over 30,000 cycles shown in Fig. 7 d. Although $100 \%$ of initial specific capacitance maintains after 10,000 cycles, it starts to obviously decrease after further cycling. Only about $70 \%$ of the initial capacitance can be still retained after 30,000 continuous charge-discharge cycles. Moreover, the agglomerate structure of this electrode materials was seriously damaged, compared with that of ZnO-CoO@NC in Fig. 7b. The comparison further confirms the importance of the protective carbon layer in $\mathrm{ZnO}-\mathrm{CoO} @ \mathrm{NC}$. In order to better understand the reason of outstanding cycling stability of $\mathrm{ZnO}-\mathrm{CoO} @ \mathrm{NC}$ in $\mathrm{KOH}$ electrolyte, we further confirmed the $\mathrm{NC}$ on $\mathrm{ZnO}-\mathrm{CoO}$ crystals throughout the mesoporous assembled spheres, not only on the surface of spheres, by using the combination of five instruments of TG-DSC-FTIR-GCMS, as shown in Fig. S7.

Further, an ASC was fabricated by using the $\mathrm{ZnO}$ CoO@NC and graphene as the positive and negative electrodes, respectively, as well as the PVA/KOH gel as the solid electrolyte and separator. The graphene electrode was prepared on the basis of the principle of charge balance according to the $\mathrm{CV}$ curves of graphene and $\mathrm{ZnO}-\mathrm{CoO} @ \mathrm{NC}$ at $20 \mathrm{mV} \mathrm{s}^{-1}$ (Fig. 8a). The CV curve of 

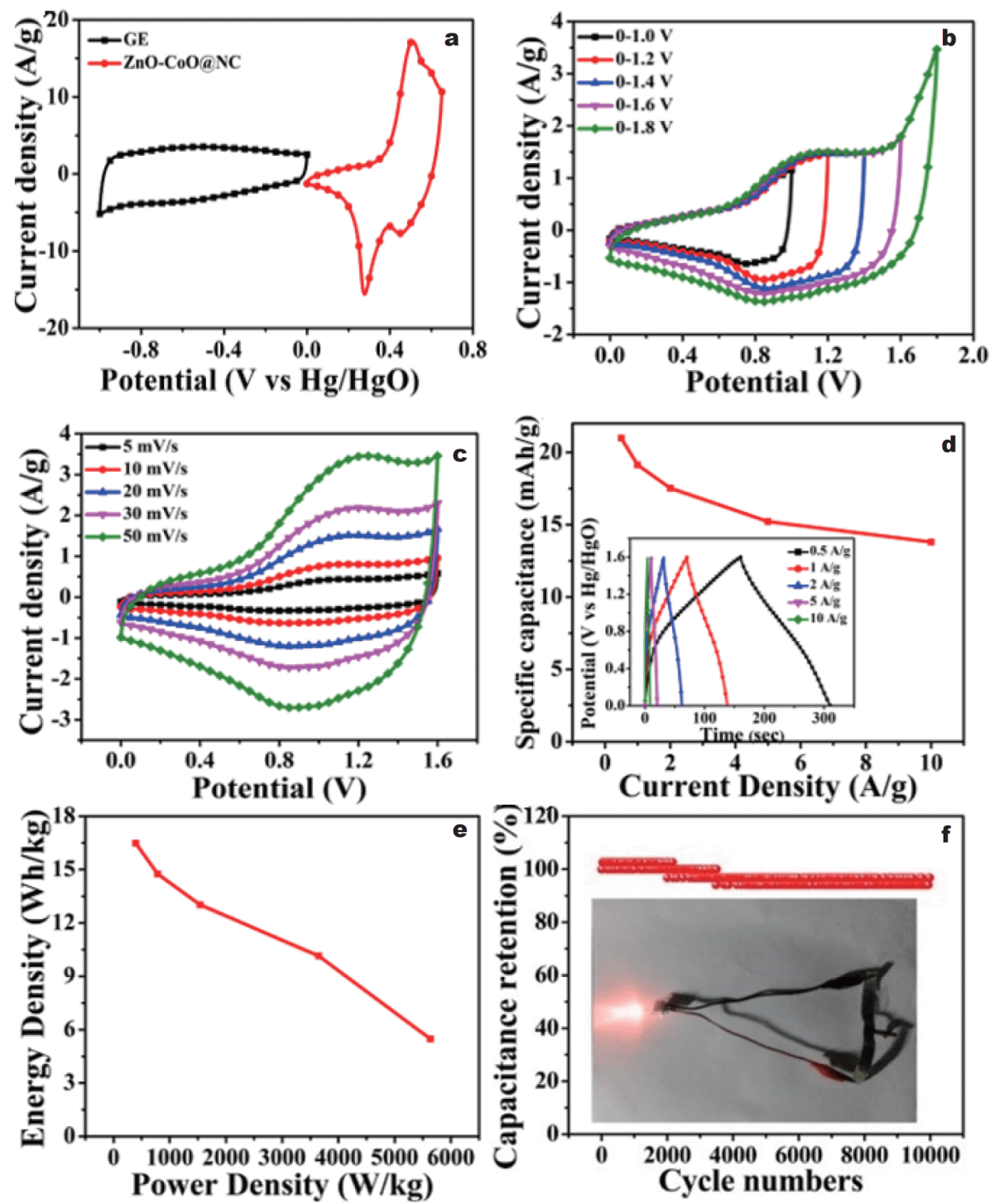

Figure 8 (a) $\mathrm{CV}$ curves of $\mathrm{ZnO}-\mathrm{CoO} @ \mathrm{NC}$ and $\mathrm{GE}$ at $20 \mathrm{mV} \mathrm{s}^{-1}$. (b) $\mathrm{CV}$ curves of GE//ZnO-CoO@NC ASC measured at $20 \mathrm{mV} \mathrm{s}^{-1}$ in various potential ranges; (c) CV curves at $5-50 \mathrm{mV} \mathrm{s}^{-1}$ in the range of $0-1.6 \mathrm{~V}$; (d) specific capacitances at different current densities with the GCD curves inserted; (e) Ragone plots of the ASC; (f) cyclic stability measured at $2 \mathrm{~A} \mathrm{~g}^{-1}$. And the insert (f) is the lighted LED bulb.

the graphene electrode (GE) exhibits a typical rectangular shape without obvious distortion when the scan rate increases from 5 to $50 \mathrm{mV} \mathrm{s}^{-1}$ (Fig. S8a), indicating the excellent electrochemical reversibility with no obvious redox peaks, indicating a typical characteristic of the electric double-layer capacitive materials. The linear and symmetrical GCD curves at various current densities from 0.5 to $10 \mathrm{~A} \mathrm{~g}^{-1}$ (Fig. S8b), and the excellent rate performance of the capacitance (Fig. S8c) also prove graphene is the typical double-layer capacitive material. According to the equation: $m^{-}=m^{+} \times\left(C^{+} \times \Delta V^{+}\right) /\left(C^{-} \times\right.$ $\left.\Delta V^{-}\right)$( $m$ is the active mass of the electrode, $C$ is the areal specific capacitance, and $\Delta V$ is the working potential window), the average mass of $\mathrm{ZnO}-\mathrm{CoO} @ \mathrm{NC}$ is $3 \mathrm{mg} \mathrm{cm}$ and thus the loading mass of graphene is $3.5 \mathrm{mg} \mathrm{cm}^{-2}$.

To estimate the appropriate operating potential of the ASC of GE//ZnO-CoO@NC, a series of CV curves with different potential windows from 1.0 to $1.8 \mathrm{~V}$ at a scan rate of $20 \mathrm{mV} \mathrm{s}^{-1}$ were performed (Fig. 8b). The CV curves are stable even at voltages up to $1.6 \mathrm{~V}$. While the $\mathrm{CV}$ curves exhibit obvious distortion when the potential is higher than $1.6 \mathrm{~V}$, which can be ascribed to some irreversible reactions [42]. Thus, we chose an operation 
voltage window of $1.6 \mathrm{~V}$ to further investigate the electrochemical performance of the as-fabricated ASC in our subsequent research. Fig. $8 \mathrm{c}$ exhibits the typical CV curves of GE//ZnO-CoO@NC at various scan rates of 5, $10,20,30$ and $50 \mathrm{mV} \mathrm{s}^{-1}$ in the voltage window from 0 to $1.6 \mathrm{~V}$. There is no obvious distortion when the scan rate increases, suggesting the desirable fast charge/discharge property and excellent rate capability of the ASC.

The specific capacitance of the GE//ZnO-CoO@NC ASC derived from the discharge curves shown in the inset of Fig. 8d presents a good rate capability. To further illustrate the energy and power property of the as-fabricated ASC, Ragone plot according to the charge/discharge measurement at different current densities is presented in Fig. 8e. The GE//ZnO-CoO@NC ASC exhibits an energy density of $16.5 \mathrm{~W} \mathrm{~h} \mathrm{~kg}^{-1}$ at a power density of $396.51 \mathrm{~W} \mathrm{~kg}^{-1}$, which still remains $5.5 \mathrm{~W} \mathrm{~h} \mathrm{Kg}^{-1}$ at a high power density of $5634.5 \mathrm{~W} \mathrm{~kg}^{-1}$. Additionally, the energy and power density of the assembled device are compared with many other reported all-solid-state ASCs, such as $\mathrm{CNO}-\mathrm{ZnO} / / \mathrm{ZnO}\left(10 \mathrm{~W} \mathrm{~h} \mathrm{~kg}^{-1}, 8 \mathrm{~kW} \mathrm{~kg}^{-1}\right)$ [44], C/CoO200//C-300 (25.04 $\left.\mathrm{W} \mathrm{h} \mathrm{kg}^{-1}, 7 \mathrm{~kW} \mathrm{~kg}^{-1}\right)$ [45] and $\mathrm{ZCO} / /$ AC $\left(23.8 \mathrm{~W} \mathrm{~h} \mathrm{~kg}^{-1}, 1.3 \mathrm{~kW} \mathrm{~kg}^{-1}\right)$ [16].

In order to further explore the practical application potential of our ASC based on GE//ZnO-CoO@NC, cyclic stability was measured at $2 \mathrm{~A} \mathrm{~g}^{-1}$ for 10,000 cycles, as shown in Fig. 8f. After 10,000 cycles, about $94 \%$ of the initial capacitance is still retained. The excellent cycling stability suggests that the well-matched configuration of GE//ZnO-CoO@NC and the synergetic effect among the carbon coating and $\mathrm{ZnO}-\mathrm{CoO}$ nanobricks significantly improve the electrical properties and the mechanical stability of the ASC. In addition, a circuit design composed of a red LED with a rated voltage of $1.8 \mathrm{~V}$ (charged to $2.0 \mathrm{~V}$ ) and two-tandem ASC devices are demonstrated in Fig. 8f. The LED can light for about $3 \mathrm{~min}$ and then become weaker in brightness. Moreover, it can be repeatable charged-discharged for several times. This phenomenon indicates the potential application of our allsolid-state device.

The good capacitive performance and excellent cycling stability of the obtained product can be ascribed to the following merits. First, the mesoporous structure from the decomposition of PVP and metal carbonate nanobricks not only increases the amount of electroactive sites but also shortens the diffusion paths for both electrons and electrolyte ions, which contributes to the superior rate capability. Second, abundant oxygen vacancies on the surface of $\mathrm{ZnO}-\mathrm{CoO}$ contribute to the enhanced electrochemical performance. The ratio of Co to $\mathrm{Zn}$ is 2:1 in
Fig. S2, indicating a dominant role of $\mathrm{CoO}$ contributing to the oxygen vacancies of $\mathrm{ZnO}-\mathrm{CoO} @ \mathrm{NC}$ [46]. Third, the relatively high conductive $\mathrm{ZnO}$ scaffold for $\mathrm{CoO}$ leads to a very fast electron transfer kinetics for the whole electrode and hence the high performance is obtained. Then, the uniformity and the integrity of the microspheres favourably alleviate the pulverization and aggregation of the electrode material as well as relieve the local volume change during the constant discharge/ charge process. Therefore the cycle stability is improved subsequently [47]. Most importantly, the NC layer coated on the $\mathrm{ZnO}-\mathrm{CoO}$ nanobricks also plays a decisive role in obtaining the excellent cycle stability. We can also conclude that the synergistic effect occurs when combining oxygen vacancy with carbon layer, and can promote both pseudocapcitance and conductivity. The introduction of oxygen vacancy can effectively improve the rate performance and the carbon layer makes great contribution to the enhancement of specific capacitance $[48,49]$.

\section{CONCLUSIONS}

In summary, the uniformly assembled $\mathrm{ZnO}-\mathrm{CoO} @ \mathrm{NC}$ oval mesoporous microspheres composed of prism nanobricks are successfully prepared for long-term cycling stable supercapacitors through a facile hydrothermal method followed by an annealing process. This work also highlights the importance of PVP which plays multifunctional roles in controlling the growth of metal compound crystals, acting as the precursor of NC, and producing abundant oxygen vacancies in ZnO-CoO@NC. The optimized ZnO-CoO@NC possesses remarkable electrochemical performance with good rate capability and excellent cyclic stability ( $92 \%$ of the initial capacitance after 40,000 cycles at $2 \mathrm{~A} \mathrm{~g}^{-1}$ ) due to its high conductivity, rich oxygen vacancies and mesoporous structure. The GE//ZnO-CoO@NC ASC also shows an outstanding cyclic stability with $94 \%$ initial capacitance after 10,000 cycles at $2 \mathrm{Ag}^{-1}$. The excellent electrochemical performance especially the outstanding cyclic stability enables $\mathrm{ZnO}-\mathrm{CoO} @ \mathrm{NC}$ to be a promising electrode material for the next generation energy storage devices. The synthetic strategy in current work also provides a general approach for fabricating the electrode materials with high performance based on redox oxides.

\section{Received 8 February 2020; accepted 15 April 2020; \\ published online 24 June 2020}

1 Li M, Xiao $\mathrm{H}$, Zhang $\mathrm{T}$, et al. Activated carbon fiber derived from sisal with large specific surface area for high-performance supercapacitors. ACS Sustain Chem Eng, 2019, 7: 4716-4723 
2 Meng Q, Cai K, Chen $\mathrm{Y}$, et al. Research progress on conducting polymer based supercapacitor electrode materials. Nano Energy, 2017, 36: 268-285

3 Muzaffar A, Ahamed MB, Deshmukh K, et al. A review on recent advances in hybrid supercapacitors: Design, fabrication and applications. Renew Sustain Energy Rev, 2019, 101: 123-145

4 Li K, Zhang J. Recent advances in flexible supercapacitors based on carbon nanotubes and graphene. Sci China Mater, 2018, 61: 210232

5 Sun W, Xiao L, Wu X. Facile synthesis of $\mathrm{NiO}$ nanocubes for photocatalysts and supercapacitor electrodes. J Alloys Compd, 2019, 772: 465-471

6 Liu T, Zhang L, You W, et al. Core-shell nitrogen-doped carbon hollow spheres $/ \mathrm{Co}_{3} \mathrm{O}_{4}$ nanosheets as advanced electrode for highperformance supercapacitor. Small, 2018, 14: 1702407

7 Ren $\mathrm{X}$, Fan $\mathrm{H}$, Ma J, et al. Hierarchical $\mathrm{Co}_{3} \mathrm{O}_{4} / \mathrm{PANI}$ hollow nanocages: synthesis and application for electrode materials of supercapacitors. Appl Surf Sci, 2018, 441: 194-203

8 Lin J, Liu Y, Wang Y, et al. Rational construction of nickel cobalt sulfide nanoflakes on $\mathrm{CoO}$ nanosheets with the help of carbon layer as the battery-like electrode for supercapacitors. J Power Sources, 2017, 362: 64-72

9 Zhou C, Zhang Y, Li Y, et al. Construction of high-capacitance 3D CoO@polypyrrole nanowire array electrode for aqueous asymmetric supercapacitor. Nano Lett, 2013, 13: 2078-2085

10 Gao Z, Song N, Li X. Microstructural design of hybrid CoO@NiO and graphene nano-architectures for flexible high performance supercapacitors. J Mater Chem A, 2015, 3: 14833-14844

11 Huang S, Yang L, Gao M, et al. Free-standing 3D composite of $\mathrm{CoO}$ nanocrystals anchored on carbon nanotubes as high-power anodes in Li-ion hybrid supercapacitors. J Power Sources, 2019, 437: 226934

12 Zhang X, Zhang R, Xiang C, et al. Polydopamine-assisted formation of $\mathrm{Co}_{3} \mathrm{O}_{4}$-nanocube-anchored reduced graphene oxide composite for high-performance supercapacitors. Ceramics Int, 2019, 45: $13894-13902$

13 Chen $\mathrm{H}$, Wang J, Han $\mathrm{X}$, et al. Facile synthesis of mesoporous $\mathrm{ZnCo}_{2} \mathrm{O}_{4}$ hierarchical microspheres and their excellent supercapacitor performance. Ceramics Int, 2019, 45: 8577-8584

14 Ouyang $\mathrm{Y}, \mathrm{Xia} \mathrm{X}, \mathrm{Ye} \mathrm{H}$, et al. Three-dimensional hierarchical structure ZnO@C@NiO on carbon cloth for asymmetric supercapacitor with enhanced cycle stability. ACS Appl Mater Interfaces, 2018, 10: 3549-3561

15 Lo IH, Wang JY, Huang KY, et al. Synthesis of $\mathrm{Ni}(\mathrm{OH})_{2}$ nanoflakes on $\mathrm{ZnO}$ nanowires by pulse electrodeposition for high-performance supercapacitors. J Power Sources, 2016, 308: 29-36

16 Zhou H, Fu W, Muhammad M, et al. Self-assembled microspheres composed of porous $\mathrm{ZnO} / \mathrm{CoO}$ nanosheets for aqueous hybrid supercapacitors. J Phys D-Appl Phys, 2019, 52: 505501

17 Kumar Y, Kim HJ. Effect of time on a hierarchical corn skeletonlike composite of CoO@ZnO as capacitive electrode material for high specific performance supercapacitors. Energies, 2018, 11: 3285

18 Wang $\mathrm{Y}$, Zhou $\mathrm{T}$, Jiang $\mathrm{K}$, et al. Reduced mesoporous $\mathrm{Co}_{3} \mathrm{O}_{4}$ nanowires as efficient water oxidation electrocatalysts and supercapacitor electrodes. Adv Energy Mater, 2015, 4: 1400696

19 Zhai T, Xie S, Yu M, et al. Oxygen vacancies enhancing capacitive properties of $\mathrm{MnO}_{2}$ nanorods for wearable asymmetric supercapacitors. Nano Energy, 2014, 8: 255-263

20 Lu X, Zeng Y, Yu M, et al. Oxygen-deficient hematite nanorods as high-performance and novel negative electrodes for flexible asymmetric supercapacitors. Adv Mater, 2014, 26: 3148-3155

21 Dillip GR, Banerjee AN, Anitha VC, et al. Oxygen vacancyinduced structural, optical, and enhanced supercapacitive performance of zinc oxide anchored graphitic carbon nanofiber hybrid electrodes. ACS Appl Mater Interfaces, 2016, 8: 5025-5039

22 Hou C, Hou Y, Fan Y, et al. Oxygen vacancy derived local build-in electric field in mesoporous hollow $\mathrm{Co}_{3} \mathrm{O}_{4}$ microspheres promotes high-performance Li-ion batteries. J Mater Chem A, 2018, 6: 69676976

23 Kim HS, Cook JB, Lin $\mathrm{H}$, et al. Oxygen vacancies enhance pseudocapacitive charge storage properties of $\mathrm{MoO}_{3-x}$. Nat Mater, 2017, 16: $454-460$

24 Li CC, Yin XM, Wang TH, et al. Morphogenesis of highly uniform $\mathrm{CoCO}_{3}$ submicrometer crystals and their conversion to mesoporous $\mathrm{Co}_{3} \mathrm{O}_{4}$ for gas-sensing applications. Chem Mater, 2009, 21: 4984-4992

25 Liu H, Zhang B, Shi H, et al. Hydrothermal synthesis of monodisperse $\mathrm{Ag}_{2} \mathrm{Se}$ nanoparticles in the presence of PVP and $\mathrm{KI}$ and their application as oligonucleotide labels. J Mater Chem, 2008, 18: 2573-2580

26 Jiao X, Xia X, Liu P, et al. Nickel cobaltite nanosheets strongly anchored on boron and nitrogen co-doped graphene for highperformance asymmetric supercapacitors. Nanotechnology, 2017, 28: 315403

27 Wu ZS, Winter A, Chen L, et al. Three-dimensional nitrogen and boron co-doped graphene for high-performance all-solid-state supercapacitors. Adv Mater, 2012, 24: 5130-5135

28 Cheng Y, Huang L, Xiao X, et al. Flexible and cross-linked Ndoped carbon nanofiber network for high performance freestanding supercapacitor electrode. Nano Energy, 2015, 15: 66-74

29 Liu G, Shao J. Pomegranate-like CoO@nitrogen-doped carbon microspheres with outstanding rate behavior and stability for lithium storage. J Mater Chem A, 2017, 5: 9801-9806

30 Yang $\mathrm{P}, \mathrm{Xiao} \mathrm{X}, \mathrm{Li} \mathrm{Y}$, et al. Hydrogenated $\mathrm{ZnO}$ core-shell nanocables for flexible supercapacitors and self-powered systems. ACS Nano, 2013, 7: 2617-2626

31 Lan D, Chen $\mathrm{Y}$, Chen $\mathrm{P}$, et al. Mesoporous $\mathrm{CoO}$ nanocubes@continuous 3D porous carbon skeleton of rose-based electrode for high-performance supercapacitor. ACS Appl Mater Interfaces, 2014, 6: 11839-11845

32 Gao R, Li Z, Zhang X, et al. Carbon-dotted defective $\mathrm{CoO}$ with oxygen vacancies: A synergetic design of bifunctional cathode catalyst for $\mathrm{Li}-\mathrm{O}_{2}$ batteries. ACS Catal, 2016, 6: 400-406

33 Wang J, Wang Z, Huang B, et al. Oxygen vacancy induced bandgap narrowing and enhanced visible light photocatalytic activity of ZnO. ACS Appl Mater Interfaces, 2012, 4: 4024-4030

34 Liu J, Yang T, Wang DW, et al. A facile soft-template synthesis of mesoporous polymeric and carbonaceous nanospheres. Nat Commun, 2013, 4: 2798

35 Li F, Xing $\mathrm{Y}$, Huang $\mathrm{M}$, et al. $\mathrm{MnO}_{2}$ nanostructures with threedimensional (3D) morphology replicated from diatoms for highperformance supercapacitors. J Mater Chem A, 2015, 3: 7855-7861

36 Zeng W, Wang L, Shi $\mathrm{H}$, et al. Metal-organic-framework-derived $\mathrm{ZnO@C@NiCo} \mathrm{O}_{4}$ core-shell structures as an advanced electrode for high-performance supercapacitors. J Mater Chem A, 2016, 4: 8233-8241

37 Koczkur KM, Mourdikoudis S, Polavarapu L, et al. Polyvinylpyrrolidone (PVP) in nanoparticle synthesis. Dalton Trans, 2015, 44: 17883-17905

38 Tomboc GM, Jadhav HS, Kim H. PVP assisted morphology-con- 
trolled synthesis of hierarchical mesoporous $\mathrm{ZnCo}_{2} \mathrm{O}_{4}$ nanoparticles for high-performance pseudocapacitor. Chem Eng J, 2017, 308: 202-213

39 Shi S, Zhuang X, Cheng B, et al. Solution blowing of $\mathrm{ZnO}$ nanoflake-encapsulated carbon nanofibers as electrodes for supercapacitors. J Mater Chem A, 2013, 1: 13779-13788

40 Ouyang Y, Huang R, Xia X, et al. Hierarchical structure electrodes of $\mathrm{NiO}$ ultrathin nanosheets anchored to $\mathrm{NiCo}_{2} \mathrm{O}_{4}$ on carbon cloth with excellent cycle stability for asymmetric supercapacitors. Chem Eng J, 2019, 355: 416-427

41 Yao D, Ouyang $\mathrm{Y}$, Jiao $\mathrm{X}$, et al. Hierarchical $\mathrm{NiO} @ \mathrm{NiCo}_{2} \mathrm{O}_{4}$ coreshell nanosheet arrays on $\mathrm{Ni}$ foam for high-performance electrochemical supercapacitors. Ind Eng Chem Res, 2018, 57: 6246-6256

42 Ouyang $\mathrm{Y}, \mathrm{Ye} \mathrm{H}$, Xia X, et al. Hierarchical electrodes of $\mathrm{NiCo}_{2} \mathrm{~S}_{4}$ nanosheets-anchored sulfur-doped $\mathrm{Co}_{3} \mathrm{O}_{4}$ nanoneedles with advanced performance for battery-supercapacitor hybrid devices. J Mater Chem A, 2019, 7: 3228-3237

43 Zong $\mathrm{Q}$, Yang $\mathrm{H}$, Wang $\mathrm{Q}$, et al. Three-dimensional coral-like

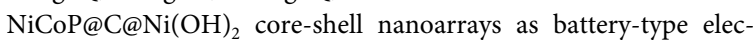
trodes to enhance cycle stability and energy density for hybrid supercapacitors. Chem Eng J, 2019, 361: 1-11

44 Mohapatra D, Parida S, Badrayyana S, et al. High performance flexible asymmetric $\mathrm{CNO}-\mathrm{ZnO} / / \mathrm{ZnO}$ supercapacitor with an operating voltage of $1.8 \mathrm{~V}$ in aqueous medium. Appl Mater Today, 2017, 7: 212-221

45 Long JY, Yan ZS, Gong Y, et al. MOF-derived Cl/O-doped C/CoO and $\mathrm{C}$ nanoparticles for high performance supercapacitor. Appl Surf Sci, 2018, 448: 50-63

46 Liu J, Wu J, Zhou C, et al. Single-phase $\mathrm{ZnCo}_{2} \mathrm{O}_{4}$ derived $\mathrm{ZnO}-$ $\mathrm{CoO}$ mesoporous microspheres encapsulated by nitrogen-doped carbon shell as anode for high-performance lithium-ion batteries. J Alloys Compd, 2020, 825: 153951

47 Wang Q, Du J, Zhu Y, et al. Facile fabrication and supercapacitive properties of mesoporous zinc cobaltite microspheres. J Power Sources, 2015, 284: 138-145

48 Wang YC, Li WB, Zhao L, et al. MOF-derived binary mixed metal/ metal oxide@carbon nanoporous materials and their novel supercapacitive performances. Phys Chem Chem Phys, 2016, 18: 17941-17948

$49 \mathrm{Lu} \mathrm{X}, \mathrm{Yu} \mathrm{M}$, Wang G, et al. $\mathrm{H}-\mathrm{TiO}_{2} @ \mathrm{MnO}_{2} / / \mathrm{H}-\mathrm{TiO}_{2} @ \mathrm{C}$ core-shell nanowires for high performance and flexible asymmetric supercapacitors. Adv Mater, 2013, 25: 267-272

Acknowledgements This work was supported by the National Natural Science Foundation of China (21576138 and 51572127), China-Israel Cooperative Program (2016YFE0129900), the Program Foundation for Science and Technology of Changzhou, China (CZ20190001), the Priority Academic Program Development of Jiangsu Higher Education Institutions, and the Program for Science and Technology Innovative Research Team in the Universities of Jiangsu Province, China. We also thank Dr. Huaping Bai and Dr. Wanying Tang at the Analysis and Test Center, Nanjing University of Science and Technology for the XRD and Raman data collection.

Author contributions Yao D, Lei W and Hao Q took part in the whole process of the research and article preparation. Wang F and Hua Y did the synthetic experiments of a part of materials and conducted part of the characterization. Xia X characterized the chemical structures of the materials. Liu J participated in the discussion and gave valuable suggestions.
Conflict of interest The authors declare no conflict of interest.

Supplementary information Supplementary data are available in the online version of the paper.

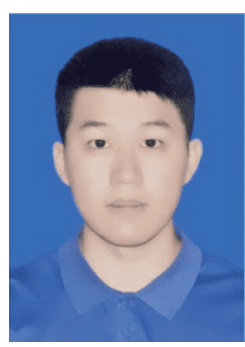

Di Yao is a $\mathrm{PhD}$ candidate at the School of Chemical Engineering under the supervision of Prof. Qingli Hao at Nanjing University of Science and Technology. His research interests focus on the development of novel materials, structures and characterization methods for the application in electrochemical energy storage.

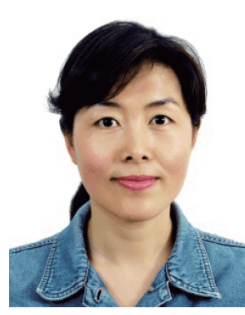

Qingli Hao is a professor in materials chemistry at Nanjing University of Science and Technology. She received her PhD degree in chemistry from the University of Regensburg, Germany, in 2003. Her research interest focuses on functional nanomaterials and their applications in energy storage and conversion systems and chemical sensors.

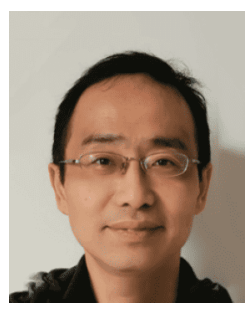

Wu Lei is a professor in applied chemistry at Nanjing University of Science and Technology. $\mathrm{He}$ received his $\mathrm{PhD}$ degree in applied chemistry from Nanjing University of Science and Technology in 2006. His research interest focuses on functional materials and their applications in environment and energy fields.

氧空位改善超稳定性氮掺杂碳包覆的氧化锌-氧 化钴介孔微球应用于非对称超级电容器

姚迪 ${ }^{1}$, 王福蕾 ${ }^{1}$, 雷武 ${ }^{*}$, 华艳 ${ }^{1}$, 夏锡锋 ${ }^{1}$, 刘金平 ${ }^{2}$, 郝青丽 $^{1 *}$

摘要 赝电容材料的周期循环稳定性是高性能超级电容器追求的 目标. 本文采用水热结合退火后处理的方法, 以聚乙烯吡咯烷酮 $(\mathrm{PVP})$ 为锌钴氧化物微球的结构导向剂、氮掺杂碳的前驱体以及 大量氧空位的还原剂前躯体, 自组装含有丰富氧空位且包覆氮掺 杂碳的介孔氧化锌-氧化钴微球 ( $\mathrm{ZnO}-\mathrm{CoO} @ \mathrm{NC})$. XPS结果证明了 材料表面氧空位的产生是由于导电氮掺杂碳的还原作用, 同时进 一步证实了金属离子与氧原子之间较弱的相互作用. 在 $2 \mathrm{~mol} \mathrm{~L}^{-1}$ $\mathrm{KOH}$ 电解质中 $\mathrm{ZnO}-\mathrm{CoO} @ \mathrm{NC}$ 电极表现出良好的电容性能, 特别是 在 $2 \mathrm{~A} \mathrm{~g}^{-1}$ 的电流密度下 40000 次充放电循环后, 电极材料仍保持 $92 \%$ 的初始电容, 显示出良好的循环稳定性, 同时材料的形貌不变. ZnO-CoO@NC正极与石墨烯负极组装的非对称超级电容器(ASC) 也具有良好的循环稳定性, 在 $2 \mathrm{~A} \mathrm{~g}^{-1}$ 的电流密度下循环 10000 次后, 可以保持 $94 \%$ 的初始电容. 介孔结构、丰富的氧空位、导电氧化锌 支架与氧化钴形成的氧化锌-氧化钻异质结构以及覆盖在多金属氧 化物纳米颗粒表面的高导电性氮掺杂碳层使得自组装得到的 $\mathrm{ZnO}$ $\mathrm{CoO} @ \mathrm{NC}$ 复合材料具有优异的电化学性能. $\mathrm{ZnO}-\mathrm{CoO} @ N C$ 有望应 用于高性能储能设备领域. 